\title{
Radio-colouration of diamond: a spectroscopic study *
}

\author{
Lutz Nasdala $^{\text {a,*}, ~ D i e t e r ~ G r a m b o l e ~}{ }^{\text {b }}$, Manfred Wildner ${ }^{\text {a }}$, Alexander M. Gigler ${ }^{c}$, \\ Thomas Hainschwang d, Alexander M. Zaitsev ${ }^{\text {e }}$, Jeffrey W. Harris ${ }^{\mathrm{f}}$, Judith Milledge ${ }^{\mathrm{g}}$, \\ Daniel J. Schulze ${ }^{\text {h }}$, Wolfgang Hofmeister ${ }^{i}$, Walter A. Balmer ${ }^{j}$ \\ ${ }^{a}$ Institut für Mineralogie und Kristallographie, Universität Wien, Althanstr. 14, A-1090 Wien, Austria \\ ${ }^{\mathrm{b}}$ Institut für Ionenstrahlphysik und Materialforschung, Helmholtz-Zentrum Dresden-Rossendorf, D-01314 Dresden, \\ Germany

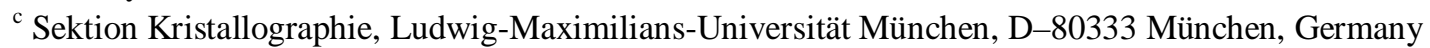 \\ ${ }^{\mathrm{d}}$ Gemlab Gemological Laboratory, LI-9496 Balzers, Liechtenstein \\ ${ }^{\text {e }}$ Department of Engineering Science \& Physics, College of Staten Island, Staten Island, NY 10314, U.S.A. \\ ${ }^{\mathrm{f}}$ School of Geographical and Earth Sciences, University of Glasgow, Glasgow G12 8QQ, United Kindgom \\ ${ }^{\mathrm{g}}$ Department of Earth Sciences, University College London, London WC1E 6BT, United Kingdom \\ ${ }^{\mathrm{h}}$ Department of Geology, University of Toronto Mississauga, Toronto, ON M5S 3B1, Canada \\ ${ }^{\text {i } I n s t i t u t ~ f u ̈ r ~ G e o w i s s e n s c h a f t e n, ~ J o h a n n e s ~ G u t e n b e r g-U n i v e r s i t a ̈ t ~ M a i n z, ~ D-55099 ~ M a i n z, ~ G e r m a n y ~}$ \\ ${ }^{j}$ Department of Geology, Faculty of Science, Chulalongkorn University, Bangkok 10330, Thailand
}

* This article is dedicated to George Bosshart (1943-2012), who since the late 1980's had devoted most of his research activities to the study of processes causing natural and artificial green diamond colouration. His contributions to diamond research have stimulated also the investigation presented here.

\section{ABSTRACT}

We have undertaken a study of the common green or orange-brown spots at the surface of rough diamond specimens, which are caused by alpha particles emanating from radioactive sources outside the diamond. Richly coloured haloes represent elevated levels of structural damage, indicated by strong broadening of the main Raman band of diamond (from initially $\sim 1.7$ to well above $30 \mathrm{~cm}^{-1}$ ), intense strain birefringence, and up-doming of spots due to their extensive volume-expansion. Green radio-colouration was analogously generated through the irradiation of diamond with $8.8 \mathrm{MeV}$ helium ions in a Tandem accelerator. The generation of readily visible radio-colouration was observed after irradiating diamond with $\geq 10^{15} \mathrm{He}$ ions per $\mathrm{cm}^{2}$, which corresponds to a total of at least $\sim 10^{10}$ alpha particles for typically sized natural spots. The accumulation of such a high number of alpha particles requires irradiation of the diamond from a radioactive source over long periods of time; presumably hundreds of millions of years in many cases. In the samples irradiated with He ions, amorphisation was observed in volume areas where the defect density exceeded $5 \times 10^{-3} \AA^{-3}$ (or $0.03 \mathrm{dpa}$ ); graphitisation as a direct result of the ion-irradiation was not observed. The green colouration transformed to brown at moderate annealing temperatures (here $450{ }^{\circ} \mathrm{C}$ ). The colour transformation is associated with only partial recovery of the radiation damage. The colour change is mainly due to the destruction of the GR1 centre, explained by trapping of vacancies (that become mobile at moderate temperatures) at A defects in the diamond to form the $\mathrm{H} 3$ centre. An activation energy of $\sim 2.4 \mathrm{eV}$ was determined for the GR1 reduction. The H3 centre, in turn, causes intense yellowish green photoluminescence under ultraviolet illumination. Radio-colouration and associated H3 photoluminescence are due to point defects in the diamond lattice created by the $\mathrm{MeV}$ ions irradiated, whereas lattice ionisation is of minor importance. This is concluded from the depth distribution of the colouration and the photoluminescence (which corresponds to the defect density but not the ionisation distribution pattern). The implanted He ions themselves seem to be negligible, as radio-colouration and H3 
emission were analogously produced through irradiation of diamond with $\mathrm{C}$ ions. The photoluminescence emission becomes observable at extremely low defect densities on the order of $10^{-6} \AA^{-3}$ (or $0.000006 \mathrm{dpa}$ ) and is suppressed at moderate defect densities of $\sim 5 \times 10^{-4} \AA^{-3}$ (or $\sim 0.003 \mathrm{dpa}$ ). Intensely brown-coloured diamond hence does not show the $\mathrm{H} 3$ emission anymore. Anneals up to $1600{ }^{\circ} \mathrm{C}$ have reduced considerably irradiation damage and radio-colouration, but the structural reconstitution of the diamond (and its de-colouration) was still incomplete.

Keywords: diamond; radiation damage; radio-colouration; defect luminescence; volume swelling

\section{Introduction}

The optical properties of diamond and their modification upon irradiation have been studied extensively for decades (Collins, 1974; Walker, 1979; Davies, 1999; Zaitsev, 2001; and references therein). Diamond is a unique mineral with many technical applications. It is an electrical insulator material (except for the rare Type IIb diamond which has semiconducting properties) with the highest density of atoms, the highest thermal conductivity at room temperature, and the highest hardness, of all solids known; furthermore it is extremely inert chemically and does not corrode (Field, 1979). Not only the increasing number of enhancement procedures applied to high-quality stones as most valuable gem material, but especially the many industrial applications - especially of chemical vapour deposition (CVD) grown diamond films - in electronics, thermal management, cutting tools, abrasives, resistant coatings, optics, and many more areas, have motivated a large number of studies addressing structural modifications of diamond upon irradiation techniques (e.g., Kalish and Prawer, 1998). In contrast, relatively few studies have addressed the natural irradiation of diamond in geological milieus thus far (e.g., Meyer et al., 1965; Vance and Milledge, 1972; Mendelssohn et al., 1979; Armitage, 1993; Vicenzi et al., 2002; Kagi et al., 2007). In these studies, irradiation effects have been dealt with mainly because natural diamond commonly shows irradiation-induced colouration (and related luminescence emission) due to the action of alpha particles.

Diamond specimens with surficial spots, or even coats, of green or brown radio-colouration, are found in many kimberlites and alluvial deposits (Meyer et al., 1965; Vance et al., 1973; Wang et al., 2006; Rubanova et al., 2009; Ustinov et al., 2009). The green colouration is generally interpreted as being due to alpha radiation emanating from radioactive substances (i.e., minerals or fluids) located in direct contact with, or in close proximity to, the diamond surface. This conclusion was for instance based on the early observation that exposure of diamond to radium salts produced grass green to dark green colour (Crookes, 1904; Lind and Bardwell, 1923). It was reconfirmed later in alpha irradiation-experiments (Vance and Milledge, 1972), which resulted in analogous green colouration of diamond. As a result of the alpha irradiation lasting over geological periods of time, natural diamond crystals may contain considerable concentrations of the radiogenic ${ }^{4} \mathrm{He}$ predominantly in their outermost layers (Verchovsky et al., 1993; Shelkov et al., 1998).

After heating to temperatures of a few hundred ${ }^{\circ} \mathrm{C}$ only, the green radio-colouration turns orangebrown (Vance and Milledge, 1972). Consequently, the accumulation of the radiation damage in green radio-coloured spots or crusts can only have started under comparably "cold” conditions, i.e., following diamond emplacement near the Earth's surface (Mendelssohn et al., 1979). The observation of brownish radio-coloured spots or crusts (which show a characteristic yellowish-green luminescence emission upon excitation with ultraviolet light), in turn, points to a thermal event in the diamond's history following the He-irradiation (Vance et al., 1973).

Diamond specimens show radio-colouration (and, if applicable, the related defect luminescence) mostly on their outer surface. Internal radio-haloes are comparably rare; they have been observed mostly inside carbonado specimens. The latter were interpreted by Vincenzi et al. (2002) as result of a secondary infiltration of the polycrystalline diamond with uranium-bearing fluids. Fukura et al. (2005) reported 
circular haloes around pores in carbonado; these pores were interpreted to be filled previously with radioactive inclusions of unknown age and origin. The observation of radio-haloes inside diamond singlecrystals (e.g., Armitage 1993), in contrast, has been reported in a few cases only. This is likely due to the sparseness of radioactive inclusions entrapped in diamond crystals. Mantle zircon (which may substitute minor amounts of actinides, in particular uranium), for instance, is an occasional accessory mineral in kimberlitic rocks (Kresten et al., 1975; Belousova et al., 1998; Page et al., 2007). However, the occurrence of zircon as inclusion inside diamond (e.g., Kinny and Meyer, 1994) is of extreme rarity.

The aim of the present paper is to review the alpha-particle related radio-colouration and -emission of diamond, in a detailed spectroscopic study of naturally alpha-coloured and ion-irradiated samples. The methods applied include optical absorption, Raman, and photoluminescence (PL) spectroscopy, as well as optical and atomic force microscopy (AFM), and Monte Carlo simulations. Note that our study focuses solely on the short-range effects of alpha irradiation, whereas the still controversial, rare irradiationinduced green body-colouration of diamond (which might only be explained by a longer-range process such as beta radiation; e.g., Bosshart, 1989), is not covered here.

\section{Materials and methods}

\subsection{Samples and preparation}

Diamond samples investigated in this study comprised first a suite of rough, unprepared stones (most of them belong to the common Type IaA) that show a range of different, natural green or orangebrown radio-colouration features. These specimens are up to $6.5 \mathrm{~mm}$ in the largest dimension in size and weigh 0.010-0.081 g (0.049-0.406 carats). They came from sources in Namaqualand (Republic of South Africa, RSA), the Central African Republic (CAR), Barou De Manoles and Jatobá (Brazil), Guaniamo (Venezuela), and Phang Nga (Thailand).

Second, three plane-parallel diamond slices polished on both sides were prepared and subjected to ion irradiation. For the preparation of the slices, we selected two large Type IaA stones from Langhoogte, Namaqualand, RSA, weighing $0.062 \mathrm{~g}$ (0.311 carats) and $0.192 \mathrm{~g}$ (0.962 carats; two slices were prepared from the latter). Both of these specimens showed natural radio-colouration spots at their surface. Spotted stones were selected for the preparation of the slices to be irradiated, to make sure that the target material was susceptible to becoming radio-coloured upon ion-irradiation.

Spectroscopic depth profiling of ion irradiated solids is normally done in two different ways, namely z-scans through the irradiated surface of transparent target materials, or lateral line scans of sections prepared after the irradiation experiment perpendicular to the surface irradiated (i.e., in the plane of the incident irradiation; e.g. Mendelssohn et al., 1979). Both of these procedures, however, are assessed to be of limited use in our case. First, spectroscopic z-scanning is tainted with a notable loss in the volume resolution performance. It is done by focussing deeper into the sample, which results in degradation of the focus and finally in increases of both the waist diameter and the z-extension of the sample volume analysed (Everall, 2000; Baldwin and Batchelder, 2001; Everall et al., 2007; Nasdala et al., 2010, 2012). Second, the preparation of sections of diamond after the irradiation of this mineral is impractical because preparation of diamond specimens (including laser-cutting and/or abrasive procedures) is likely connected with uncontrolled up-heating of the sample, which in turn may result in unrecognised annealing of the radiation damage. To eliminate these two uncertainties, samples were finally prepared before the irradiation experiment, in a way that allowed us to do spectroscopic profiling after the irradiation experiment without the need for further preparation steps (Fig. 1). Note that profiling along the ion-irradiation direction is hence done using a lateral spectroscopy scan. This is of great advantage, as the lateral resolution of a confocal spectrometer system (commonly described by the Rayleigh limit of $1.22 \lambda / 2 \mathrm{NA}$; with $\lambda=$ wavelength and NA = numerical aperture of the objective used) is much better than its depth of focus ( $4 \lambda /$ $\mathrm{NA}^{2}$ ). 
The preparation of samples to be irradiated consisted of two steps. First, specimens were laser-cut and two large, plane-parallel windows were ground and polished. The orientations of the cuts - parallel to (110) for the small stone and parallel to (100) for the large stone - were chosen depending on the rough stones' shapes, i.e., to get slices with exceptionally large lateral dimensions. The final thicknesses between the two parallel windows were in the range $0.36-0.50 \mathrm{~mm}$. Second, on the longer sides of each slice, two polished windows were applied perpendicular to the slice's main surfaces.

\subsection{Ion-irradiation and annealing experiments}

Ion-irradiation experiments were done at the nuclear reaction analysis beamline of the $5 \mathrm{MV}$ Tandem accelerator facility of the Helmholtz-Zentrum Dresden (formerly Forschungszentrum DresdenRossendorf), Germany. Note that since our experiments this accelerator has been decommissioned, being replaced recently by a modern HVEE (High Voltage Engineering Europe B.V.) 6 MV Tandetron accelerator.

Targets (i.e., diamond slices to be irradiated) were carefully cleaned, attached to a copper plate, and loaded into a vacuum sample chamber $\left(\sim 10^{-8} \mathrm{mbar}\right)$. During the irradiation experiment they were cooled with liquid nitrogen $\left(-196^{\circ} \mathrm{C}\right)$. The ion beam was focused to a rectangular area of about $1 \mathrm{~mm}^{2}$ size. It was directed always with an angle of $\sim 7^{\circ}$ to the normal of the sample surface, so as to ensure a "random" orientation and minimize potential ion-channelling effects (e.g., Raineri et al., 1991) along [110] or [100], respectively. Samples were irradiated with $8.8 \mathrm{MeV}^{4} \mathrm{He}^{2+}$ ions. This ion energy was chosen because it is equivalent to one of the 23 common alpha energies in the ${ }^{238} \mathrm{U},{ }^{235} \mathrm{U}$, and ${ }^{232}$ Th chains $(8.8$ $\mathrm{MeV}$ is the highest among those 23 energies, corresponding to alpha particles produced in the ${ }^{212} \mathrm{Po} \rightarrow$ ${ }^{208} \mathrm{~Pb}$ decay within the ${ }^{232} \mathrm{Th}$ chain). Irradiation fluences were varied in the range $10^{13}-10^{17} \mathrm{He}$ ions $/ \mathrm{cm}^{2}$, which was achieved by varying the exposure times to the beam between $\sim 2.8$ seconds and $\sim 8$ hours.

It had been discussed before that helium itself may form an emission centre (e.g., Tkachev et al., 1985). We were therefore obliged to check whether or not the implanted He ions contribute to the radiocolouration and/or defect emission. This can be done by irradiating the sample with another atomic species; ideally with one that is already present in the target. Additional irradiation experiments were therefore done with $22.5 \mathrm{MeV}^{12} \mathrm{C}^{4+}$ ions (fluences $10^{13}-10^{16} \mathrm{C}$ ions $/ \mathrm{cm}^{2}$ ). The comparably higher ion energy was chosen because $8.8 \mathrm{MeV}^{12} \mathrm{C}$ ions penetrate only $\sim 3.9 \mu \mathrm{m}$ into a diamond target. The penetration depth is clearly higher $(\sim 11.1 \mu \mathrm{m})$ for $22.5 \mathrm{MeV}^{12} \mathrm{C}$ ions, which allowed us to place Raman and luminescence analyses well within the irradiated sample volume.

Thermal annealing of the ion-irradiated diamond slices was done at 450, 500, 550, 600, 700, 1000, 1300 , and $1600{ }^{\circ} \mathrm{C}$. Spectra were obtained after each individual annealing step, and the same slices were then heated again. Slices were placed in a graphite container and brought in a vacuum chamber $(4.5-7 \times$ $10^{-6}$ mbar; except for the $1600^{\circ} \mathrm{C}$ experiment which was done at $\left.2 \times 10^{-5} \mathrm{mbar}\right)$. The heating was done for 8-10 hours ( $450-1000^{\circ} \mathrm{C}$ experiments) and 5 hours $\left(1300\right.$ and $\left.1600{ }^{\circ} \mathrm{C}\right)$, respectively.

\subsection{Analytical methods and data reduction}

Samples were first inspected under a binocular microscope, with $6 \times-40 \times$ magnification, using different combinations of transmitted and reflected light illumination. Images of the radio-colouration were taken using an Olympus DP 70 digital camera attached to a modified Olympus BX series microscope. Images of the PL in the visible range (i.e., $>400 \mathrm{~nm}$ wavelength) were taken with the same system, which was equipped with ultraviolet (UV) transmitting objectives. For the latter, samples were photographed under broad Hg-lamp illumination ( $<370 \mathrm{~nm}$ wavelength) in the reflected light mode.

The assignment of the diamond types was made based on $\mathrm{N}$ and $\mathrm{H}$ bands obtained in Fouriertransform infrared (FTIR) absorption spectra; for more details see Hainschwang et al. (2009). Spectra in the range $400-7500 \mathrm{~cm}^{-1}\left(4 \mathrm{~cm}^{-1}\right.$ resolution) were obtained by means of a Perkin Elmer Spectrum BX2 system. 
Optical absorption spectra were measured at room temperature in the spectral range 36,000-6,000 $\mathrm{cm}^{-1}$ using an IR-scopeII mirror-optics microscope attached to a Bruker IFS66v/S FTIR spectrometer. A quartz beam-splitter and appropriate combinations of light sources and detectors were used. Each final spectrum hence consists of a combination of three sub-spectra, which were obtained in the following wavenumber ranges: 36,000-19,000 $\mathrm{cm}^{-1}$ (Xe lamp source; GaP detector; spectral resolution $25 \mathrm{~cm}^{-1}$; 1024 scans), 19,000-10,000 $\mathrm{cm}^{-1}$ (W lamp; Si detector; spectral resolution $10 \mathrm{~cm}^{-1}$; 512 scans), and 10,000$6,000 \mathrm{~cm}^{-1}$ (W lamp; Ge detector; spectral resolution $10 \mathrm{~cm}^{-1}$; 512 scans). Sub-spectra were aligned in absorbance for perfect match, if necessary. Circular areas $170 \mu \mathrm{m}$ in diameter were analysed in transmission geometry. Optical absorption spectra were always obtained in pairs, namely of the ionirradiated (i.e., radio-coloured) area and a nearby, non-irradiated area of the same diamond (both were measured versus air as background). The difference of these two spectra yielded effective spot spectra (i.e., the radio-coloured spot versus the respective bulk diamond taken as background; cf. Fig. 3 below).

Spectra were evaluated quantitatively using the OPUS software (version 6, 2004; Bruker Optik $\mathrm{GmbH}$, Ettlingen, Germany). For the evaluation, the spectral range between $6,500 \mathrm{~cm}^{-1}$ and an upper boundary with still admissible signal-to-noise ratio (mostly 29,000 $\mathrm{cm}^{-1}$; lower in case of high absorbances) was selected. Subsequently, a "rubberband" correction using polynomials with 8-16 manually set anchor points was applied, in order to extract a "corrected" spectrum showing distinct and assignable spectral absorption features superimposed on a more or less featureless, smoothly evolving background absorption (the latter increasing generally towards the ultraviolet UV region). Integral absorbances of specific spectral features were calculated using the program's interactive integration function ('type A' integration for baseline-grounded broad bands, 'type B' integration for narrow superimposed bands). Likewise, the integral absorbance of the background absorption was calculated for the range $25,000-8,000 \mathrm{~cm}^{-1}$ ('type A' integration) after applying a zero-offset correction to the linear absorbance values. For the highest irradiation fluences $\left(10^{17} \mathrm{He} / \mathrm{cm}^{2}, 10^{16} \mathrm{C} / \mathrm{cm}^{2}\right)$, where the absorption intensity exceeded the instrumental detection limit (i.e., absorbance $\approx 3$ ) already within the visible range, respective integral absorbances were obtained for restricted spectral ranges $(17,000-8,000$ or $13,500-8,000$ $\left.\mathrm{cm}^{-1}\right)$.

Room-temperature Raman measurements, including point analyses and line scans, were obtained by means of a dispersive Horiba Jobin Yvon LabRam-HR spectrometer equipped with Olympus BX41 optical microscope, a diffraction grating with 1,800 grooves/mm in the beam path, and Si-based, Peltiercooled charge-coupled device (CCD) detector. Spectra were excited with the He-Ne $632.8 \mathrm{~nm}$ emission (3 $\mathrm{mW}$ at the sample). A $100 \times$ objective (NA $=0.90$ ) was used, and the system was operated in the confocal mode. The lateral resolution was $\sim 1 \mu \mathrm{m}$. The system was calibrated using the Rayleigh line and Ne lamp emissions. The wavenumber accuracy was better than $0.5 \mathrm{~cm}^{-1}$, and the spectral resolution was determined at $\sim 0.8 \mathrm{~cm}^{-1}$. Band fitting was done after appropriate manual background correction, assuming a Lorentzian-Gaussian band shape. Actual full widths at band half-maximum (FWHMs) were calculated by correcting the measured FWHMs for the apparatus function of the Raman system (i.e., for the experimental band broadening), according to the simplified procedure of Dijkman and van der Maas (1976; for details see Nasdala et al., 2001b). Total uncertainties of corrected FWHMs are assessed to vary between $\pm 0.2 \mathrm{~cm}^{-1}$ (narrow bands with FWHMs $<3 \mathrm{~cm}^{-1}$ ) and $\pm 0.5 \mathrm{~cm}^{-1}$ (FWHMs in the range $3-6 \mathrm{~cm}^{-1}$ ).

Photoluminescence spectra in the visible and near infrared range (up to $1000 \mathrm{~nm}$ wavelength) were obtained in quasi-reflection mode at $-196^{\circ} \mathrm{C}$ (using liquid $\mathrm{N}_{2}$ ) with two systems. First, a modified Adamas SAS 2000 system equipped with Ocean Optics Maya 2000 Pro spectrometer was used. Samples were placed in an integrating sphere and excited with an unfocused laser beam (473 nm or $532 \mathrm{~nm}$ DPSS laser, $500 \mathrm{~mW}$ ); measurements were done in reflection mode. The spectral resolution was $\sim 0.9 \mathrm{~nm}$. Second, a quasi-confocal Renishaw RM 1000 system equipped with Leica DMLM optical microscope and Linkam cooling stage (ZnSe window) was used. Spectra were taken with a He-Cd laser beam (325 nm excitation) focused to the sample surface through an OFR $5 \times$ UV objective with $35 \mathrm{~mm}$ free working distance (NA = 0.13). The emission was registered in $135^{\circ}$ geometry respective to the excitation, using a $50 \times$ objective 
with $10.6 \mathrm{~mm}$ free working distance $(\mathrm{NA}=0.55)$. The lateral resolution was better than $3 \mu \mathrm{m}$, and the spectral resolution was $\sim 0.1 \mathrm{~nm}$.

The surface topographies of radio-haloes were studied using a WiTec alpha300 A AFM equipped with large-scan range $\left(100 \times 100 \times 20 \mu \mathrm{m}^{3}\right)$ piezo-driven scan stage. Scans were made in the contact mode (constant force).

\section{Results and discussion}

\subsection{Naturally radio-coloured diamond}

Natural diamond samples normally show their (green or orange-brown) radio-colouration in the form of surficial spots (Fig. 2). These spots are mostly circular (Figs. 2d, g, i, j) or at least roundish (Figs. $2 \mathrm{a}-\mathrm{c}, \mathrm{h}$ ), and typically several tens of micrometres in diameter. Typically there are no sharp margins of the radio-colouration; individual spots rather have a diffuse appearance with gradual colour decrease toward the surrounding diamond host (cf. especially Fig. 2b, left halo, and Figs. 2c, g, j). In contrast to common radio-colouration haloes in other minerals such as biotite (Gentry, 1974; Nasdala et al., 2001a), chlorite (Pal, 2004), cordierite (Voznyak et al., 1996; Nasdala et al., 2006), or fluorite (Schilling, 1926), radiocolouration spots at the surface of diamond grains typically do not show any central inclusion or other indication of their causal source of radioactivity. One of the extremely rare exceptions is presented in Figure 2d. Here, each of the green radio-haloes has a well-defined circular margin and shows a tiny dark entity of unknown composition in its centre. The latter is interpreted as a remnant or at least "fingerprint relict” of a central, He-emitting grain or crystal. A similar observation was made by Koivula (2000) who reported the discovery of tiny crystals of radioactive minerals in the centres of spherical green radio-haloes in diamond fragments from Zimbabwe. Koivula (2000) was able to identify loparite-(Ce) and chevkinite(Ce) from Raman spectra; he assigned the radioactivity causing the radio-colouration to the elevated Th content of these two inclusion minerals. For the vast majority of radio-haloes, however, the source of the radioactivity cannot be observed and remains unknown.

All of the radio-colouration patterns described above are consistent with the common assumption that the radioactivity causing the radio-colouration was emitted from a relatively small source (i.e., each individual spot was induced by a small radioactive grain) in close proximity to the diamond surface. These radioactive phases probably had sizes on the order of between several micrometers to a few tens of micrometers. Helium emanation from a smaller source on the order of a micrometre would result in the formation well-defined colouration rings (actually interlaced hollow spheres) with radii corresponding to alpha energies (e.g., Gentry, 1974); helium emanation from much bigger radioactive sources would result in larger haloes.

Apparent crusts of radio-coloured diamond mostly turned out to consist of a multitude of individual spots (Figs. 2f, k, l), indicating the former presence of many small, radioactive grains neighbouring the diamond. More or less homogeneously coloured crusts, in contrast, point to effects of radioactive fluids. A most unusual staining pattern is shown in Figure 2e. Here, elongate radio-coloured areas several tens of micrometers wide form a meshwork pattern that was interpreted by Bosshart (2009) as virtual effigy of grain boundaries of minerals that existed previously adjacent to the diamond. This author assigned the observed pattern to diamond irradiation due to radioactive fluids circulating in the diamond's natural environment. He proposed that mineral phases (such as Fe and Mn oxides and hydroxides) precipitated from fluids especially in gaps of intersecting grain boundaries, and then acted as adsorbers of radium ions and their radioactive progenies (Bossart, 2009). All of the observations above are consistent with the common interpretation that the radio-colouration under discussion was created by alpha particles, because radii of round spots as well as half-widths of elongate network areas are on the order of penetration depth of alpha particles (with larger haloes being indicative of radioactive sources of comparably larger sizes). 
Corresponding to the colouration visible with the unaided eye, optical absorption spectra obtained from a range of natural radio-haloes fall into two major groups. Absorption of green spots (Fig. 3a) is characterised by three main features: an absorption continuum that increases gradually toward the UV, a broad absorption band with a maximum near $\sim 16,100 \mathrm{~cm}^{-1}$, and a narrow band at $\sim 19,820 \mathrm{~cm}^{-1}$ (due to its small integral, the latter however does not contribute notably to the visible colouration). Absorption spectra of orange-brown spots (Fig. 3b) show two general differences, compared to those of green spots, namely absence of the $\sim 16,100 \mathrm{~cm}^{-1}$ band and a notably flatter slope of the absorption edge, resulting in proportionately higher absorption in the blue range $\left(20,000-25,000 \mathrm{~cm}^{-1}\right)$.

The absorption continuum with its gradual increase toward the UV (Fig. 3) is a common feature of irradiated diamond (e.g., Khomich et al., 2007). Although its nature is not well understood, it is generally assumed that its origin is similar to that of defects in brown diamond, i.e., vacancy clusters (Fisher, 2009; see also Zaitsev, 2001; and references therein). Note that the absorption of radio-coloured haloes in biotite and cordierite (Nasdala et al., 2001a, 2006) shows a similar continuum. The generally higher absorption of the darkened radio-haloes in all three minerals is mainly due to a significant shift of the absorption edge by several thousand $\mathrm{cm}^{-1}$ from the UV toward the visible range, when compared to the absorption spectrum of the respective neighbouring host (cf. bulk and spot spectra in Fig. 3). The $\sim 16,100 \mathrm{~cm}^{-1}$ band is due to GR1 absorption (Clark and Walker, 1973; Field, 1979; Zaitsev, 2001; for the energy and nomenclature of defect centres in diamond see also Bridges et al., 1990). The centre is assigned to a neutral vacancy $\left(\mathrm{V}^{0}\right)$ created by irradiation (GR = general radiation). Its zero-phonon line (ZPL) lies at $\sim 13495 \mathrm{~cm}^{-1}(740.9 \mathrm{~nm}$ wavelength), and its strong electron-phonon coupling causes absorption to $>18,000 \mathrm{~cm}^{-1}$. The narrow band observed at $\sim 19,820 \mathrm{~cm}^{-1}$ is assigned to the ZPL of the $3 \mathrm{H}$ centre $\left(\sim 19,860 \mathrm{~cm}^{-1}\right.$; $503.4 \mathrm{~nm}$ wavelength), a typical radiation-induced self-interstitial defect (Walker, 1979; Steeds et al., 1999, 2000), which may however be created also by plastic deformation.

The colouration of green spots can hence be summarised as a corporate effect of the increase of the absorption continuum toward shorter wavelengths and the vibronic GR1 band, bracketing a "window" of reduced absorption in the green range (absorption minimum around 19,250 $\mathrm{cm}^{-1}$, or $520 \mathrm{~nm}$ wavelength), whereas orange-brown spots are coloured due to the enhanced absorption continuum in the blue range. It should be added that absorption spectra of host diamonds show, besides the "regular" continuum and absorption edge in the UV, a narrow band at $\sim 24,055 \mathrm{~cm}^{-1}$ accompanied by a broad vibronic structure with a maximum around $26,000 \mathrm{~cm}^{-1}$ (bulk spectra in Figs. 3a,b). This absorption is assigned to the common N3 centre, a cluster of three $N$ interstitials associated with a vacancy (ZPL 24,080 $\mathrm{cm}^{-1}$, cf. Zaitsev 2001 and references therein). Further nitrogen-related absorptions observed include narrow bands at $\sim 28,975$ $\mathrm{cm}^{-1}$ (N4 centre) and $\sim 31,650 \mathrm{~cm}^{-1}$ (N6 centre). All of these defects, however, do not contribute notably to the total absorption of the host diamonds, which appeared more or less colourless.

The degree of structural disorder due to radiation damage of radio-coloured areas was evaluated using Raman spectroscopy. A quantitative calibration of Raman spectral changes dependent on the degree of radiation damage, exists only for the mineral zircon thus far (cf. Nasdala et al., 2001b; and references therein). The Raman technique has however also been used already to study, rather qualitatively, radiation damage in several other minerals such as monazite (Seydoux-Guillaume et al., 2002; Nasdala et al., 2010; Ruschel et al., 2012), titanite (Beirau et al., 2010), fergusonite (Tomašić et al., 2006), and cordierite (Nasdala et al., 2006; Weikusat et al., 2010). In general, structural radiation damage results in gradual FWHM increases, changes of spectral positions mostly toward lower Raman shifts, and intensity losses of the "crystalline" Raman bands, which eventually disappear at the highest damage stage. The same trends are well known for neutron- and ion-irradiated diamond (Dooley et al., 1993; Fontaine et al., 1994; Yagiu et al., 1995; Hanzawa et al., 1996), whereas naturally radio-spotted diamond, to the best of our knowledge, has not been studied using Raman spectroscopy thus far. It should be noted, however, that FWHM increases associated with band down-shifts are also observed upon tensile stress (Knight and White, 1989) and at decreasing particle sizes of $\leq 2 \mu \mathrm{m}$ (Yoshikawa et al., 1993); the latter effect is even more pronounced at high incident laser energies (Nachalnaya et al., 1994; Zhao et al., 1998). Compression, in contrast, results in band up-shifts. Associated FWHM increases are assigned to non-hydrostatic stress 
(Sharma et al., 1985; Knight and White, 1989), or in general to distortion from the perfect cubic structure (Huong, 1991). Finally, FWHM increases observed may - however to a minor extent - also be due to chemical impurities (Surovtsev et al. 1999).

Due to the high point-group symmetry of its crystal structure, diamond shows only one first-order Raman band at $\sim 1332 \mathrm{~cm}^{-1}$, which has a narrow FWHM of $\sim 1.6 \mathrm{~cm}^{-1}$ (Solin and Ramdas, 1970). It is especially in the semiconductor literature - commonly referred to as $L O=T O$ mode (e.g., De Wolf et al., 1998): optical vibrations are degenerate, and longitudinal-transverse splitting does not occur. This nomenclature is also used in the present paper. In Raman spectra obtained from green and brown radiocoloured spots (not shown), the $L O=T O$ band was observed clearly broadened with respect to its counterpart in the un-irradiated host, with correspondingly lowered intensity and slightly down-shifted spectral position (Raman shifts down to $\sim 1325 \mathrm{~cm}^{-1}$ ). The highest $L O=T O$ band broadening (FWHMs up to $>20 \mathrm{~cm}^{-1}$ ) was observed in centres of intensely coloured spots. These spectral changes are remarkably pronounced, compared to the rather moderate Raman spectral changes observed from radio-haloes in other minerals [for instance, Nasdala et al. (2006) found that intensely radio-coloured haloes in cordierite are associated with FWHM increases of silicate-group related Raman bands of only $\left.\leq 6 \mathrm{~cm}^{-1}\right]$. Even though conclusions by analogy among different minerals need to be regarded with caution, the clear Raman band broadening observed indicates a relatively high level of structural damage present. In the samples analysed in this study, we have however neither found any radio-colouration halo in which the $L O=T O$ band of diamond was not observed at all, nor we obtained clear Raman signals of amorphous or disordered graphitic carbon (compare Bhatia et al., 1998; Prawer et al., 1998).

The comparably severe degree of radiation damage in radio-coloured haloes was already indicated by microscopic observations. First, radio-haloes show notable (i.e., up to $1^{\text {st }}$ order yellowish white) strain birefringence colours in cross-polarised light (not shown here; compare p. 79 in Koivula, 2000). Second, under reflected light with low-angular illumination, radio-haloes appear bulgy (Figs. 4a-b), which indicates significant volume expansion in the radiation-damaged sample volumes (compare Prins et al., 1986; Dooley et al., 1993; Bosia et al., 2010). This was measured by AFM topographic scans; we found that the surface up-doming lies on the order of several tenths of micrometre (Fig. 4c). Strain birefringence and surface swelling were observed for both green and brown radio-colouration spots, indicating that the green-to-brown transition at elevated temperatures cannot be associated with (nearly) complete structural reconstitution of the diamond.

\subsection{Ion-irradiated diamond}

The three polished diamond slices were subjected to five $8.8 \mathrm{MeV}$ He irradiations $\left(10^{13}-10^{17}\right.$ ions $\left./ \mathrm{cm}^{2}\right)$ and for comparison also to four $22.5 \mathrm{MeV} \mathrm{C}$ irradiations $\left(10^{13}-10^{16} \mathrm{ions} / \mathrm{cm}^{2}\right)$; i.e., three irradiations placed at different areas were done per slice. Only irradiations with $\geq 10^{15} \mathrm{He} / \mathrm{cm}^{2}$ (and $\geq 10^{14}$ $\mathrm{C} / \mathrm{cm}^{2}$ ) resulted in notable green colouration whereas the colour change of the area irradiated with $10^{14}$ $\mathrm{He} / \mathrm{cm}^{2}$ (and the area irradiated with $10^{13} \mathrm{C} / \mathrm{cm}^{2}$ ) was extremely weak and not readily visible with the unaided eye. This is visualised in Figure 8 below: The upper left image shows a diamond slice after irradiation with $10^{14} \mathrm{~cm}^{-2}$ (area marked with small black arrows) and $10^{17} \mathrm{~cm}^{-2}$ (area showing dark green colouration); however the extremely weak radio-colouration of the former is not visible at all in the photograph. Our results are apparently in slight contrast to the early findings of Vance and Milledge (1972) who observed "very pale green" colouration at $\sim 10^{14} \mathrm{He} / \mathrm{cm}^{2}$, which is remarkable especially because these authors used less energetic and hence less destructive He ions in their irradiation experiments (5.3 MeV alpha particles from a ${ }^{210} \mathrm{Po}$ source). Vance et al. (1973) even determined the minimum dose of $5.5 \mathrm{MeV}$ He particles required to generate visible green colouration at between $3 \times 10^{13}$ and $1 \times 10^{14} \mathrm{ions} / \mathrm{cm}^{2}$. We may speculate that minor differences in the chemical compositions of the samples irradiated by Vance et al. (1973) and in the present study have resulted in somewhat different susceptibilities to radio-colouration (Zaitsev, 2001). However, an adequate explanation for the relatively clear difference between the results of Vance et al. (1973) and ours (about one order of magnitude) cannot be given at this stage. As our 
irradiations were done at liquid-nitrogen temperature, immediate self-annealing (and hence colouration decrease) during the irradiation experiments can be excluded.

All optical absorption spectra obtained from He- and C-irradiated spots (Fig. 5) show the same major features as described above for naturally green-spotted diamond: an absorption continuum that increases gradually toward the UV, a broad GR1 vibronic band at around $\sim 16,100 \mathrm{~cm}^{-1}$, (its ZPL is seen as weak shoulder near 13,490 $\mathrm{cm}^{-1}$ ), and a narrow $3 \mathrm{H}$ band at $\sim 19,820 \mathrm{~cm}^{-1}$ (with weak vibrational features at 19,980 and $20,340 \mathrm{~cm}^{-1}$ ). It should be mentioned that at $\geq 10^{16} \mathrm{He} / \mathrm{cm}^{2}$, an additional weak band at 9,280 $\mathrm{cm}^{-1}$ (1078 $\mathrm{nm}$ wavelength) was observed. This centre has been mentioned as possible multi-vacancy complex generated in ion-irradiated, nitrogen containing diamond (Zaitsev, 2001). The total absorption does not increase linearly with the dose but rather shows a logarithmic dependence. For instance, from optical absorption spectra of the spots irradiated with $10^{14}$ and $10^{16} \mathrm{He} / \mathrm{cm}^{2}$ (compare Fig. 5), the integral of the absorption continuum (range 29,000-8,000 $\mathrm{cm}^{-1}$ ) was calculated as 950 and $15,400 \mathrm{~cm}^{-1}$, and the integral absorbance of the GR1 vibronic band was determined at 65 and $2000 \mathrm{~cm}^{-1}$, respectively. The 100fold increase of the irradiation fluence has hence resulted in an approximately $20 \times$ stronger absorption.

The wide similarity of spectra features obtained from He- and C-irradiated spots exclude the possibility that the implanted He ions themselves form an absorption centre that contributes significantly to the radio-colouration; rather the absorption increase is due to point defects created by the ions irradiated. The only marked difference between He- and C-irradiated spots is that the latter show much more intense colouration. Equivalent fluences of $22.5 \mathrm{MeV}$ C result in ca. 5-10 times stronger absorption, compared to 8.8 MeV He (Fig. 5).

In order to evaluate this observation, we calculated the stopping of $8.8 \mathrm{MeV}^{4} \mathrm{He}$ ions and 22.5 $\mathrm{MeV}^{12} \mathrm{C}$ ions in a carbon target $\left(\rho=3.52 \mathrm{~g} / \mathrm{cm}^{3}\right)$ by standard Monte Carlo simulation using the SRIM2008 code (Ziegler et al., 2008). This software package (SRIM = the Stopping and Range of Ions in Matter) predicts mathematically the transport of ions in matter, including ranges of the ions irradiated, and density and distribution of the primary vacancies generated; the calculation is based on a full quantummechanical treatment of ion-atom collisions in the target (Ziegler et al., 1985). The displacement energy was assumed to be $45 \mathrm{eV}$ (Uzan-Saguy et al., 1995; Friedland et al., 2005) whereas SRIM default values were accepted for lattice binding $(3 \mathrm{eV})$ and surface binding energies $(7.4 \mathrm{eV})$. To reach high statistical precision, trajectories for 10,000 incoming ions, irradiated into the target perpendicular to its surface, were calculated.

The creation of an average of 74 Frenkel defetcs (i.e., vacancy-interstitial pairs due to atomic displacements, diminished by immediate recombinations) per $8.8 \mathrm{MeV}$ He ion is predicted. These defects are mainly located near the ends of the He trajectories (average length $28.7 \mu \mathrm{m}$; the defect distribution is shown in Fig. 6), with a maximum of $\sim 0.005$ vacancies per $\AA$. The corresponding values calculated for $22.5 \mathrm{MeV}$ C ions are $11.1 \mu \mathrm{m}$ path length, 392 vacancies per ion, and $\sim$ maximum of 0.030 vacancies per $\AA$ (Fig. 6). The $22.5 \mathrm{MeV} \mathrm{C}$ ions are hence $>5$ times more destructive than $8.8 \mathrm{MeV}$ He ions, which explains why a clearly smaller fluence was needed to generate the same amount of defects in the target and, connected with that, the same total colouration. The much higher target ionisation by the high-energy $\mathrm{C}$ ions (maximum $257 \mathrm{eV} / \AA ̊$ compared to $70 \mathrm{eV} / \AA$ for $8.8 \mathrm{MeV}$ He ions) may also contribute to their higher damaging and radio-colouration efficiency.

Inspection of the slices irradiated under the binocular microscope through their small "sidewindows" (Fig. 1) suggested that the colouration of pale spots seemed to be concentrated in a narrow "stripe" located about $28-30 \mu \mathrm{m}\left(10^{15} \mathrm{He} / \mathrm{cm}^{2}\right.$ spot $)$ and $10-12 \mu \mathrm{m}\left(10^{14} \mathrm{C} / \mathrm{cm}^{2}\right.$ spot $)$ below the surface irradiated, respectively, with an apparently colourless volume range between this stripe and the surface irradiated. In view of the SRIM results discussed above (Fig. 6) this suggests that the coloration was created in volume areas with the highest damage density. In the case of richly coloured spots, the surficial colourless volume was not observed anymore; the entire penetration volumes appeared radio-coloured.

The damage created by $8.8 \mathrm{MeV}$ He ions, and its depth distribution, was studied by high-resolution Raman line-scans in the range $0-50 \mu \mathrm{m}$ below the surface irradiated. These point-by-point scans with a step width of $0.5 \mu \mathrm{m}$ were done through the small windows perpendicular to the surface irradiated (Fig. 1). 
Selected Raman spectra and depth profiles of spectral parameters are presented in Figure 7; results are summarised in Table 1.

The spot irradiated with $10^{13} \mathrm{He} / \mathrm{cm}^{2}$ yielded over the entire depth range, within analytical uncertainties, the same narrow $L O=T O$ band as its host (corrected FWHM 1.7-1.8 $\mathrm{cm}^{-1}$; Raman shift $\sim 1332 \mathrm{~cm}^{-1}$ ). Irradiation with $10^{14}$ and $10^{15} \mathrm{He} / \mathrm{cm}^{2}$ resulted in changes detectable with the Raman technique only near $29 \mu \mathrm{m}$ below the surface, i.e., in locations with the highest defect density. Han et al. (1993) reported that there was no detectable radiation damage after the irradiation of CVD diamond with $1.6 \times 10^{14} 5.5 \mathrm{MeV}$ He ions per $\mathrm{cm}^{2}$, as the FWHM of the $L O=T O$ band remained virtually unchanged. This is nevertheless consistent with our results; the inability of Han et al. (1993) to detect a slight FWHM increase in the narrow volume area near the ends of the He trajectories was perhaps due to their insufficient volume resolution (as these authors merely used a $6 \mu \mathrm{m}$ laser spot in their analyses). At $10^{16}$ and $10^{17}$ $\mathrm{He} / \mathrm{cm}^{2}$, the entire depth range affected by the ion irradiation showed significant Raman spectral changes (Fig. 7b). Except near $29 \mu \mathrm{m}$ below the surface, the $L O=T O$ band was obtained strongly broadened (FWHMs up to $\sim 40 \mathrm{~cm}^{-1}$ ), shifted to lower wavenumbers (down to $\sim 1310 \mathrm{~cm}^{-1}$ ), and with decreased intensity. Near $29 \mu \mathrm{m}$ below the surface, neither the Raman signal of diamond nor that of graphitic carbon was obtained (Fig. 7a), indicating local amorphisation in the diamond due to very high defect densities.

Jamieson et al. (1995) had observed FWHM values even exceeding $40 \mathrm{~cm}^{-1}$ in He-irradiated diamond (irradiations with $3.5 \mathrm{MeV}$ He with up to $3 \times 10^{17} \mathrm{ions} / \mathrm{cm}^{2}$ ), which they assigned to increasing disorder in the diamond lattice, but no amorphisation as indicated by the disappearance of the diamond signal. The complete loss of the $L O=T O$ band upon ion-irradiation has been observed, for instance, by Lee et al. (1993), Fontaine et al. (1994), and Orwa et al. (1997). Lee et al. (1993) found instead a broad asymmetric hump (maximum at $\sim 1550 \mathrm{~cm}^{-1}$, and low-wavenumber tail extending to about $1200 \mathrm{~cm}^{-1}$ ) in their Raman spectra. This feature is reminiscent to the spectrum of diamond-like carbon (DLC), and Lee et al. (1993) assigned it to the formation of highly disordered $\mathrm{sp}^{2}$ carbon resulting from heavy local irradiation damage in the diamond target. Orwa et al. (1997) described a range of (mostly broad) bands from heavily ion-irradiated diamond, in particular a very broad hump of low intensity at around $1280 \mathrm{~cm}^{-1}$ (also seen in our $29 \mu \mathrm{m}$-spectrum in Fig. 7a), which they assigned to amorphous carbon. The same $\sim 1280$ $\mathrm{cm}^{-1}$ hump was observed from ion-irradiated CVD film by Mikhailov et al. (1996). The creation of amorphous rather than graphitic carbon as a direct result of heavy ion irradiation was also verified from electron diffraction patterns obtained by Hickey et al. (2009).

Our results hence confirm the possibility of local amorphisation in diamond upon heavy ion irradiation. In contrast, diamond-graphite transformation as a direct result of the ion irradiation (reported e.g. by Gippius et al., 1999, 2003; based on optical interference measurements) was not observed in our experiments. Green radio-colouration is always associated with significant structural damage, indicated by significant Raman band broadening accompanied by band down-shift. The Raman shift of the $L O=T O$ band decreases, and its FWHM increases, linearly with the irradiation dose (Jamieson et al., 1995). The structural damage generated is assigned to point defect creation, and accumulation, in the collision cascades (Prins and Derry, 2000). In addition, the broadening and down-shift of the $L O=T O$ band may be caused in addition by dilative stress. This is presumably the case especially in the depth range directly beyond the radiation-damaged volume (i.e., at 30-35 $\mu \mathrm{m}$ below the surface irradiated; see Fig. 7b). Here, the non-irradiated diamond is stressed by the neighbouring amorphous and hence strongly radiationdamaged "stripe".

\subsection{Changes upon thermal annealing}

Annealing of the diamond slices at temperatures up to $600{ }^{\circ} \mathrm{C}$ resulted in gradual reduction of the colouration intensity and in green to orange-brown colour change of the ion-irradiated spots (Fig. 8). Correspondingly, absorption spectra of irradiated spots changed appreciably (Fig. 9a). The absorption continuum showed a general decrease in intensity over the whole range of annealing temperatures (Fig. 9b), which was connected with a back-shift of the absorption edge toward the UV. The green-to-brown 
colour transformation, however, was mainly controlled by the reduction of the GR1 vibronic band (causing absorption mainly in the range $14,000-18,000 \mathrm{~cm}^{-1}$; Fig. 9c) and the simultaneous appearance of a broad band at $\sim 21,300 \mathrm{~cm}^{-1}$ (causing absorption mainly in the range 20,000-22,500 $\mathrm{cm}^{-1}$; Fig. 9d). The latter is assigned to the vibronic structure of the $\mathrm{H} 3$ centre. This centre consists of two $\mathrm{N}$ atoms associated with a vacancy; it is typically formed in any nitrogen-containing diamond upon annealing at $\sim 500{ }^{\circ} \mathrm{C}$. The small $3 \mathrm{H}$ absorption band near $19,820 \mathrm{~cm}^{-1}$ (Fig. 5; see also the as-irradiated spectrum in Fig. 9a) was not detected anymore in any optical absorption spectra of annealed samples (Fig. 9a). This is consistent with the results of Iakoubovskii and Adriaenssens (2000) and Iakoubovskii et al. (2001) who found that most of the $3 \mathrm{H}$ absorption disappears upon annealing at well below $400{ }^{\circ} \mathrm{C}$.

Because vacancies become mobile at elevated temperatures, annealing at $\leq 600{ }^{\circ} \mathrm{C}$ has hence reduced the concentration of irradiation-created neutral vacancies (GR1). Those vacancies were trapped at an A-type nitrogen defect, hence causing formation of the H3 centre (Alekseev et al., 2000; Collins, 2005; Collins et al., 2005; Kiflawi et al., 2007; Collins and Kiflawi, 2009; and references therein) according to

$$
\mathrm{GR} 1(\mathrm{~V})^{0}+\mathrm{A}(\mathrm{N}-\mathrm{N}) \rightarrow \mathrm{H} 3(\mathrm{~N}-\mathrm{V}-\mathrm{N})^{0}
$$

It needs to be mentioned, however, that the broad absorption band at $14,000-18,000 \mathrm{~cm}^{-1}$ is not solely due to the GR1 centre. Especially in absorption spectra obtained after $700{ }^{\circ} \mathrm{C}$ annealing, a weak feature at $\sim 16,830 \mathrm{~cm}^{-1}$ (594.2 $\mathrm{nm}$ wavelength) is seen, which may be related to the " $595 \mathrm{~nm}$ centre"; and the 1000 ${ }^{\circ} \mathrm{C}$ and $1300{ }^{\circ} \mathrm{C}$ absorption spectra of spots irradiated with $\geq 10^{15} \mathrm{He} / \mathrm{cm}^{2}$ or $10^{15} \mathrm{C} / \mathrm{cm}^{2}$ showed weak bands near 15,515 and 15,665 $\mathrm{cm}^{-1}$ (644.5 and $638.4 \mathrm{~nm}$ wavelength), which may be related to the " $1.924 \mathrm{eV}$ centre" that is known from annealed, neutron-irradiated diamond (cf. Zaitsev, 2001; and references therein). All of these additional absorption features overlaying the GR1 band are however extremely weak (and cannot be seen readily in Fig. 9a), and the reduction of the whole GR1 band (Fig. 9c) shows a sharp decrease with temperature. This indicates strongly a first-order kinetic process, which can be described by equation

$$
\mathrm{X}_{\mathrm{n}}=\mathrm{X}_{\mathrm{n}-1} \exp \left\{-\left[-\mathrm{A} \exp \left(-\mathrm{E}_{\mathrm{a}} / \mathrm{kT}\right)\right] \mathrm{t}\right\}
$$

with $\mathrm{X}_{\mathrm{n}}$ and $\mathrm{X}_{\mathrm{n}-1}=$ integral absorbances after the $\mathrm{n}^{\text {th }}$ and $(\mathrm{n}-1)^{\text {th }}$ anneals, $\mathrm{A}=$ atom-hopping frequency (which is close to the maximum phonon frequency of diamond, $\sim 4 \times 10^{13} \mathrm{~s}^{-1}$ ), $\mathrm{E}_{\mathrm{a}}=$ activation energy, $\mathrm{T}=$ temperature, and $\mathrm{t}=$ time. Considering the integral absorptions determined for the GR1 vibronic band in the spectra of the spots irradiated with $10^{14}, 10^{15}$, and $10^{16} \mathrm{He} / \mathrm{cm}^{2}$ (with the absorption in the respective asirradiated spectrum set to $100 \%$ ), the best fit was achieved for an activation energy of approximately 2.4 $\mathrm{eV}$. For a more precise fit, however, additional data pairs in the temperature range $250-450{ }^{\circ} \mathrm{C}$ would be needed. The above value is nevertheless in reasonable agreement with the result of Martin et al. (1999a) who determined the activation energy for vacancy diffusion in diamond at $2.55 \pm 0.15 \mathrm{eV}$. Additional features observed at moderate annealing temperatures include a narrow band 9,280 $\mathrm{cm}^{-1}(1078 \mathrm{~nm}$ wavelength) and a broad band at $\sim 10,550 \mathrm{~cm}^{-1}$ (948 nm wavelength), which are probably due to ZPL and vibronic coupling of the "1.149 eV centre" (Zaitsev, 2001).

Anneals in the range $1000-1600{ }^{\circ} \mathrm{C}$ have resulted in further decrease of the absorption continuum (Fig. 9b) and consequently reduction of the colouration intensity. The vibronic H3 band has reached a maximum at $1000{ }^{\circ} \mathrm{C}$ and decreased at high temperatures (Fig. 9d). The resulting lower absorption in the blue range seems to be the cause of the visible change from orange-brown to rather greyish brown colouration (Fig. 8). The radio-colouration has become extremely faint, but is still well-visible with the unaided eye, after annealing for 5 hours at $1600{ }^{\circ} \mathrm{C}$ (Fig. 8). Additional spectral features observed at and above $1300^{\circ} \mathrm{C}$, which however have minor effect on the colouration observed, include a narrow band at $10,125 \mathrm{~cm}^{-1}$ (988 nm wavelength) and a broad absorption at $\sim 12,220 \mathrm{~cm}^{-1}$ (820 nm wavelength; see 1600 ${ }^{\circ} \mathrm{C}$ spectrum in Fig. 9a), which is assigned to ZPL and vibronic structure of the $\mathrm{H} 2$ centre (Clark et al., 1956).

The only exception from the trends described above showed the spot irradiated with $10^{16} \mathrm{C} / \mathrm{cm}^{2}$. This area had become non-transparent due to graphitisation after annealing at $700{ }^{\circ} \mathrm{C}$. The formation of disordered graphitic carbon in heavily irradiation-damaged sample volumes upon annealing is a common 
phenomenon (Gippius et al., 1999; Friedland et al., 2005; and references therein). Interestingly, graphitisation was only observed for the spot irradiated with $10^{16} \mathrm{C} / \mathrm{cm}^{2}$ but in contrast not in any of the He-irradiated diamond spots (including the area irradiated with $10^{17} \mathrm{He} / \mathrm{cm}^{2}$; cf. Fig. 8, upper row of images). The general threshold for graphitisation upon subsequent annealing of ion-irradiated diamond, described by the critical defect concentration $N_{c}$, was found to be on the order of $10^{22}$ vacancies $/ \mathrm{cm}^{3}$ by Uzan-Saguy et al. (1995; see also Kalish et al., 1999). Diamond has a cubic lattice (space group $F d \overline{3} m$; unit-cell constant $=3.567 \AA ; Z=8$; Kaiser and Bond, 1959) with a density of atoms of $0.176 \AA^{-3}$ (or $1.76 \times$ $10^{23} \mathrm{~cm}^{-3}$ ). The critical defect concentration $N_{c}$ value hence converts to a defect density of $\sim 0.06 \mathrm{dpa}$ (displacements per target atom). Our SRIM calculations predicted maximum defect concentrations of ca. 5 $\times 10^{-3}$ per $\AA$ per $8.8 \mathrm{MeV}$ He ion irradiated and $3 \times 10^{-3}$ per $\AA$ per $22.5 \mathrm{MeV}$ C ion irradiated, respectively (Fig. 6). For the $10^{17} \mathrm{He} / \mathrm{cm}^{2}$ (equivalent to $10 \mathrm{He} / \AA^{2}$ ) irradiation, this converts to a maximum defect density of $\sim 5 \times 10^{-2} \AA^{-3}$, or $\sim 0.28 \mathrm{dpa}$. The analogous maximum value calculated for the $10^{16} \mathrm{C} / \mathrm{cm}^{2}$ irradiation are $\sim 3 \times 10^{-2} \AA^{-3}$, or $\sim 0.17 \mathrm{dpa}$. Note that both maximum defect concentrations calculated are well above the critical $N_{c}$ value of Uzan-Saguy et al. (1995). Graphitisation of the area irradiated with $10^{16}$ $\mathrm{C} / \mathrm{cm}^{2}$ does hence correspond to earlier findings. It is however remarkable that no graphitisation upon annealing was found for the area irradiated with $10^{17} \mathrm{He} / \mathrm{cm}^{2}$, even though it had suffered an even higher maximum defect density. We are obliged to assume that $N_{c}$ depends notably on the ionic species irradiated (perhaps associated to the ratio of nuclear and electronic stopping powers). For 8.8 MeV He-ion irradiation of diamond, $N_{c}$ seems to be as high as $>5 \times 10^{22} \mathrm{~cm}^{-3}$ (or $>0.28 \mathrm{dpa}$ ). Our observation may however explain why naturally alpha-spotted diamond affected by a secondary thermal event shows colour change to orange-brown and eventually gradual decolouration, rather than graphitisation.

Raman measurements indicated that the green-to-brown colour change is merely connected with partial structural reconstitution: Brown spots, produced through annealing at $550{ }^{\circ} \mathrm{C}$, still showed about half of the initial structural disorder and damage is preserved (Table 1). This is consistent with the notable $L O=T O$ band broadening detected for natural brown spots. The incomplete recovery is especially seen by comparing the as-irradiated and $550{ }^{\circ} \mathrm{C}$ FWHMs obtained at $\sim 15 \mu \mathrm{m}$ below the surface irradiated (Table 1). The maximum damage is in contrast difficult to determine: Because of the strong gradient of the defect density at $\sim 29 \mu$ m below the surface (compare Figs. 6 and 7), the FWHM obtained changes significantly with the location of the spot analysed.

After annealing at $1600{ }^{\circ} \mathrm{C}$, irradiation-induced changes of Raman spectral parameters have mainly retrograded. Slight band broadening and down-shift (on the order of several tenth of $\mathrm{cm}^{-1}$ ) however indicates that even annealing at $1600{ }^{\circ} \mathrm{C}$ was insufficient for complete structural recovery, which seems to correspond well to the incomplete colouration decrease at this temperature (Collins et al., 2005; see Fig. 8). Except for the spot irradiated with $10^{16} \mathrm{C} / \mathrm{cm}^{2}$, annealing lead in all cases to reconstitution of the diamond lattice. This corresponds to results of Kalish et al. (1999) who found that samples with defect concentrations below the graphitisation threshold $\left(N<N_{c}\right)$ reconstituted to diamond upon annealing at elevated temperatures. Reconstitution of a completely disordered carbon phase lacking any diamond $L O=T O$ Raman signal to well-crystallised diamond mixed with diamond-like carbon was also observed by Park et al. (2011).

\subsection{Photoluminescence of irradiated diamond}

The naturally radio-coloured diamond samples showed a remarkably split behaviour when inspected under UV light illumination, which correlated with their colouration. Green spots appeared virtually non-luminescent, with the spot areas being even darker than the weakly bluish luminescent host diamond (which may either be due to suppression of the emission in the radiation-damaged areas, or simply their dark colouration). Brown spots, in contrast, showed intense yellowish green PL, especially in mildly coloured marginal areas, whereas most intensely radio-coloured centres of brown spots appeared dark. Correspondingly, our ion-irradiated areas yielded intense luminescence only after heat-treatment, especially after the $550-1300{ }^{\circ} \mathrm{C}$ runs (Fig. 10a). Up to $10^{16} \mathrm{He} / \mathrm{cm}^{2}$ and $10^{15} \mathrm{C} / \mathrm{cm}^{2}$, the luminescence 
intensity correlated with ion fluence irradiated. Even the $10^{13} \mathrm{He} / \mathrm{cm}^{2}$ was seen, though with low intensity, whereas the $10^{14} \mathrm{He} / \mathrm{cm}^{2}$ and $10^{13} \mathrm{C} / \mathrm{cm}^{2}$ spots were clearly visible under the UV microscope. This implies that visible defect luminescence requires much lower defect densities than visible radio-colouration. The most intensely radio-coloured $10^{17} \mathrm{He} / \mathrm{cm}^{2}$ and $10^{16} \mathrm{C} / \mathrm{cm}^{2}$ spots appeared dark, indicating a reversal of the defect emission at high levels of the irradiation damage.

Diamond has a band gap of $5.47 \mathrm{eV}\left(\sim 44,120 \mathrm{~cm}^{-1}\right)$ at room temperature. Electronic transitions that cause emission in the visible range therefore depend on the few impurities in diamond whose energy levels lie in the forbidden band gap. This is the case mainly for boron-, nitrogen-, and vacancy-related defects. To determine the centres responsible for the yellowish-green luminescence, PL spectra were obtained at liquid-nitrogen temperature (Fig. 10b). The emission was found to be caused mainly by the H3 centre, which has a ZPL near $\sim 19,870 \mathrm{~cm}^{-1}$ (503.2 nm wavelength; Zaitsev, 2001; and references therein) and intense electron-phonon coupling bands near 19,530 $\mathrm{cm}^{-1}, 19,215 \mathrm{~cm}^{-1}$, and 18,915 $\mathrm{cm}^{-1}$ (512.0, 520.4, and $528.7 \mathrm{~nm}$ wavelength). As discussed above, this centre is generated at $\geq 500{ }^{\circ} \mathrm{C}$ by trapping of vacancies at A-type defects. The analogous trapping of vacancies at B-type nitrogen defects has lead to the formation of the $\mathrm{H} 4$ centre (ZPL at $20,160 \mathrm{~cm}^{-1}$; $496.2 \mathrm{~nm}$ wavelength; Zaitsev, 2001). Its low intensity compared to that of the $\mathrm{H} 3$ centre is consistent with the sparseness of B centres in our Type IaA diamond specimens. Two additional, relatively narrow emissions of rather low intensity were observed at $\sim 17,390$ $\mathrm{cm}^{-1}$ (575 nm wavelength) and $\sim 15,690 \mathrm{~cm}^{-1}$ (673 nm wavelength). These are assigned to the $\mathrm{NV}^{0}$ and the $\mathrm{NV}^{-}$centre, respectively. Both are due to substitutional (either neutral or negatively charged) nitrogen associated with the nearest vacancy (Bruce et al., 2011; and references therein); they are typical of irradiated diamond that was annealed subsequently at $>550{ }^{\circ} \mathrm{C}$ (Zaitsev, 2001). Note that the $\mathrm{NV}^{0}$ centre may be confused, especially when Type IaB stones are evaluated, with an unknown radiation-induced centre that emits near 17,360 $\mathrm{cm}^{-1}$ (575.9 nm wavelength; Martin et al., 1999b; Collins and Ly, 2002). The weak broad hump at around $14,000 \mathrm{~cm}^{-1}$ (Fig. 10b) may perhaps be assigned to a still unknown PL-active defect that is commonly observed from bown Type Ia diamond, especially from samples affected by plastic defromation (De Weerdt and Collins, 2007). Note that no noticeable differences between the spectra of Heand C-irradiated spots were found, in particular no narrow emission lines in the green range that were assigned by Tkachev et al. (1985) to a He-related emission centre. The hypothesis that implanted He atoms may contribute to the luminescence emission is therefore not confirmed by our results.

The depth distribution of the defect emission of our ion-irradiated samples is visualised by photomicrographs of the "side-windows" (Fig. 1) obtained under UV illumination. Three examples are presented in Figure 11. Figure 11a shows that the emission of diamond mildly irradiated with $10^{14} \mathrm{He} / \mathrm{cm}^{2}$ is concentrated in the small depth range of high defect concentration near the ends of ion trajectories, near $\sim 29 \mu \mathrm{m}$ below the surface. To underline this correlation, the PL image is compared with the defect distribution predicted by SRIM (Fig. 6), converted to defect density and plotted on a logarithmic intensity scale, in Figure 11. It is suggested that initial defect emission is observed from areas with an extremely low defect concentration of about $10^{-6} \AA^{-3}$ (corresponding to $\sim 0.000006 \mathrm{dpa}$ ); strong luminescence intensity seems to require at least $\sim 5 \times 10^{-6} \AA^{-3}$ (or $\sim 0.00003 \mathrm{dpa}$ ). The narrow emission "stripe" observed here is in some contrast to the results of Ager et al. (1994). These authors found in a cathodoluminescence study of diamond irradiated with $5.5 \mathrm{MeV}$ He ions (fluence $8 \times 10^{15} \mathrm{ions} / \mathrm{cm}^{2}$ ) that the depth distribution of the H3 emission was substantially broadened with respect to the defect distribution profile predicted by SRIM calculation. The maximum of the $\mathrm{H} 3$ emission was observed several micrometres beyond the penetration depth of the ions irradiated. Ager et al. (1994) assigned their observations to vacancy diffusion (i.e., selfannealing) during the irradiation process. The observation of narrow luminescent stripe allows us to exclude major long-range diffusion (i.e., on the micrometre range and above) in our case. Also, it should be noted that the emission intensity observed correlates with the depth-distribution pattern of point defects created through ion irradiation, but not with the depth distribution of ionisation losses. This points strongly to a defect-related emission centre (predominantly H3 in our case) whereas direct ionisation-induced luminescence is not observed. It needs to be considered cautiously that emissions may be related to the additional ionisation of point defects, as it has been discussed by Kanada and Watanabe (2006) in a 
cathodoluminescence study of ion-irradiated diamond. The main presumption for defect luminescence, however, is the presence (of low concentrations) of point defects.

The spot irradiated with $10^{16} \mathrm{He} / \mathrm{cm}^{2}$ shows defect emission throughout the entire ion-irradiated volume except the highly damaged "stripe" near $29 \mu \mathrm{m}$ below the surface (Fig. 11b). The spot irradiated with $10^{17} \mathrm{He} / \mathrm{cm}^{2}$ shows almost no defect luminescence anymore (Fig. 11c). This behaviour and especially the depth distribution patterns observed are very similar to that of ion-irradiated zircon (cf. Fig. 6 in Nasdala et al., 2011). Radiation-damaged zircon shows, at low damage levels, the generation of a broadband yellow emission centre, which is then suppressed at moderate damage levels. A very similar, simple model can be used to explain our observations (Fig. 11): The suppression of the PL obviously occurs at still low defect densities exceeding ca. $5 \times 10^{-4} \AA^{-3}$ (corresponding to $\sim 0.003 \mathrm{dpa}$ ). The low defect level of yellowish-green emitting diamond is also confirmed by Raman measurements on naturally radio-coloured and ion-irradiated spots. Strong luminescence was found in areas with $L O=T O$ FWHMs $\leq 2.5 \mathrm{~cm}^{-1}$ whereas brownish spots with more pronounced Raman spectral changes always appeared dark. The PL of radiationdamaged diamond is hence controlled by two effects, namely, defect emission (in our Type IaA diamond mainly H3 emission) created at very low damage levels, and luminescence suppression occurring already at moderate damage levels. The latter is probably due to further disturbance of the electronic band structure, and introduction of non-radiating electronic transitions, as a result of the structural damage. Our observations suggest that strong yellowish-green $\mathrm{H3}$ emission of diamond can only exist in a relatively narrow range of low defect densities (i.e., ca. 0.00003-0.003 dpa).

\section{Implications}

We have observed the formation of an amorphous layer near the end of the $8.8 \mathrm{MeV} \mathrm{He}$ trajectories, in the two areas that were irradiated with $\geq 10^{16} \mathrm{He} / \mathrm{cm}^{2}$ (Table 1). Here (i.e., $\sim 29 \mu \mathrm{m}$ below the irradiated surface) we found a shallow region in which the diamond $L O=T O$ Raman band was not detected anymore. Considering the lateral resolution performance of our confocal Raman system, the amorphised layer must have been $>1 \mu \mathrm{m}$ in thickness (if a thinner amorphous layer in diamond is analysed, the spectrum contains also the signal of the neighbouring crystalline host). For the $10^{16} \mathrm{He} / \mathrm{cm}^{2}$ irradiation, the defect density at $\sim 29 \mu \mathrm{m}$ below the irradiated surface predicted by SRIM calculation is ca. $5 \times 10^{-3} \AA^{-3}$ (or $0.03 \mathrm{dpa}$ ), indicating that the diamond lattice collapsed after only $3 \%$ of all lattice atoms have been displaced. This value is low compared to ion-irradiation results of Spits et al. (1994) who determined the critical damage beyond which diamond is amorphised at $\geq 0.50 \mathrm{dpa}$. These authors however considered that their results may be overestimates due to insufficient assessment of vacancy-interstitial recombinations. Our value of $\sim 0.03$ dpa shows better correspondence to that of Lee et al. (1993) who estimated a defect density of less than $0.10 \pm 0.05$ dpa was required for complete diamond destruction.

Readily visible radio-colouration was observed in our experiments only after irradiating diamond with $\geq 10^{15} \mathrm{He} / \mathrm{cm}^{2}$. This result suggests that the formation of radio-colouration at the surface of natural stones must be a long-term process. Typical individual spots of naturally radio-coloured stones (Fig. 2) have sizes on the order of $10^{3} \mu \mathrm{m}^{2}$. A minimum of $\geq 10^{10}$ alpha particles are therefore needed to generate a spot with faint green radio-colouration; the generation of intensely coloured spots of the same size would require correspondingly higher amounts of alpha particles. If the alpha radiation emanated, for example, from a $\sim 5 \mu \mathrm{m}$ sized uraninite grain of circular shape (weight $\sim 7 \times 10^{-10} \mathrm{~g}$; $>88 \mathrm{wt} \% \mathrm{U}$ ), an irradiation duration of ca. 10 myr would be needed to produce weak radio-colouration in the neighbouring diamond. In the case of a $10 \mu \mathrm{m}$ sized tetragonal zircon crystal (weight $\sim 4.7 \times 10^{-9} \mathrm{~g}$ ) containing $1000 \mathrm{ppm}$ of $\mathrm{U}$, a time period of $\sim 1,170$ myr is calculated for the accumulation of $10^{10}$ alpha particles in the neighbouring diamond. This implies that the alpha activity of small zircon grains is implausible to cause rich radiocolouration in the neighbouring diamond. The generation of the radio-coloration is most likely due to the action of small grains of strongly radioactive phases located adjacent to the diamond specimen, lasting for at least several millions of years. 
It may be speculated that, as the chemical composition of diamond affects its susceptibility to radio-colouration (Zaitsev, 2001), our results cannot be applied to all types of diamond. Diamond samples with higher nitrogen content may perhaps require lower amounts of alpha particles to be come radiocolourated: For instance, Kiflawi et al. (2007) have discussed that the vacancy concentration in diamond correlates with its nitrogen content, because the strain field of nitrogen atoms prevents recombining of vacancies and interstitials. It therefore appears worthwhile to focus future studies on a quantification of the radio-colouration in dependence of both the He dose and the diamond's chemical composition. It should be considered, however, that in our study, naturally spotted stones were selected for the preparation of slices to be irradiated. Our observations indicate strongly that this initial, surficial radio-colouration must have resulted from alpha irradiation lasting over tens or even hundreds of millions of years.

\section{Acknowledgements}

DeBeers Consolidated Mines Ltd. are thanked for making available diamond specimens for irradiation experiments. Diamond crystals from Thailand were kindly provided by Somruedee Satitkune. We are grateful to Andreas Wagner and Wolfgang Zirbs for technical assistance and to Robert Stark for providing access to his laboratory for AFM measurements. Rainer Grötzschel, Viton Heera, John I. Koivula, and Heinz Surbeck are thanked for stimulating discussions. This research was supported financially by the European Commission through contract no. MEXC-CT-2005-024878 and Research Infrastructures Transnational Access (RITA) grant no. 025646, and the Austrian Science Fund (FWF) through grant P20028-N10, to L.N.

\section{References}

Ager, J.W. III, Han, S., Prussin, S.G., Wagner, R.S., Pan, L.S., Kania, D.R., Lane, S.M., 1994. Spatially resolved measurement of lattice damage in alpha-particle-irradiated type IIa natural diamond by confocal photoluminescence microscopy. J. Appl. Phys. 76, 4050-4053.

Alekseev, A.G., Amosov, V.N., Krasilnikov, A.V., Tugrainov, S.N., Frunze, V.V., Tsutskikh, A.Yu., 2000. Transformation of GR1 defects in annealed natural type IIa diamonds. Tech. Phys. Lett. 26, 1-7.

Armitage, M.H., 1993. Radioactive halos in a diamond. Am. Lab. 25, 28-30.

Baldwin, K.J., Batchelder, D.N., 2001. Confocal Raman microspectroscopy through a planar interface. Appl. Spectrosc. 517-524.

Beirau, T., Bismayer, U., Mihailova, B., Paulmann, C., Groat, L., 2010. Structural phenomena of metamict titanite: a synchrotron, X-ray diffraction and vibrational spectroscopic study. Phase Transit. 83, 694702.

Belousova, E.A., Griffin, W.L., Pearson, N.J., 1998. Trace element composition and cathodoluminescence properties of southern African kimberlitic zircons. Mineral. Mag. 62, 355-366.

Bhatia, K.L., Fabian, S., Kalbitzer, S., Klatt, C., Krätschmer, W., Stoll, R., Sellschop, J.F.P., 1998. Optical effects in carbon-ion irradiated diamond. Thin Solid Films 324, 11-18.

Bosia, F., Calusi, S., Giuntini, L., Lagomarsino, S., Lo Giudice, A., Massi, M., Olivero, P., Picollo, F., Sciortino, S., Sordini, A., Vannoni, M., Vittone, E., 2010. Finite element analysis of ion-implanted diamond surface swelling. Nucl. Instrum. Meth. B 268, 2991-2995.

Bosshart, G., 1989. The Dresden Green. J. Gemmol. 21, 351-362.

Bosshart, G., 2009. Mineralogical and physical properties and thermal instability of natural green diamond colours. GIT 2008: $2^{\text {nd }}$ Intl. Gem Jewelry Conf., Gemmol. Inst. Thailand, Bangkok, March, 2009.

Bridges, F., Davies, G., Robertson, J., Stoneham, A.M., 1990. The spectroscopy of crystal defects: a compendium of defect nomenclature. J. Phys. Condens. Mat. 2, 2875-2928.

Bruce, L.F., Kopylova, M.G., Longo, M., Ryder, J., Dobrzhinetskaya, L.F., 2011. Luminescence of diamond from metamorphic rocks. Am. Mineral. 96, 14-22. 
Clark, C.D., Walker, J., 1973. The neutral vacancy in diamond. P. Roy. Soc. Lond. A Mat. 334, 241-257.

Clark, C.D., Ditchburn, R.W., Dyer, H.B., 1956. The absorption spectra of irradiated diamonds after heat treatment. P. Roy. Soc. Lond. A Mat. 237, 75-89.

Collins, A.T., 1974. Visible luminescence from diamond. Ind. Diamond Rev. 34, 131-137.

Collins, A.T., 2005. Optical centres produced in diamond by radiation damage. New Diam. Front. C. Tec. 17, 47-61.

Collins, A.T., Ly, C.-H., 2002. Misidentification of nitrogen-vacancy absorption in diamond. J. Phys. Condens. Mat. 21, 364209.

Collins, A.T., Connor, A., Ly, C.-H., Shareef, A., Spear, P.M., 2005. High-temperature annealing of optical centers in type-I diamond. J. Appl. Phys. 97, 083517.

Collins, A.T., Kiflawi, I., 2009. The annealing of radiation damage in type Ia diamond. J. Phys. Condens. Mat. 21, 364209.

Crookes, W., 1904. On the action of radium emanations on diamond. P. R. Soc. London 74, 47-49.

Davies, G., 1999. Current problems in diamond: towards a quantitative understanding. Physica B 273-274, 15-23.

De Weerdt, F., Collins, A.T., 2007. Broad-band luminescence in natural brown type Ia diamonds. Diam. Relat. Mater. 16, 512-516.

De Wolf, I., Jiménez, J., Landesmann, J.-P., Frigeri, C., Braun, P., Da Silva, E., Calvet, E., 1998. Raman and luminescence spectroscopy for microelectronics. Catalogue of optical and physical parameters. "Nostradamus" project SMT4-CT-95-2024. Office for Official Publications of the European Communities, Luxembourg.

Dijkman, F.G., van der Maas, J.H., 1976. Dependence of bandshape and depolarization ratio on slitwidth. Appl. Spectrosc. 30, 545-546.

Dooley, S.P., Jamieson, D.N., Prawer, S., 1993. $\mathrm{He}^{+}$and $\mathrm{H}^{+}$microbeam damage, swelling and annealing in diamond. Nucl. Instrum. Meth. B 77, 484-491.

Everall, N.J., 2000. Modelling and measuring the effect of refraction on the depth resolution of confocal Raman microscopy. Appl. Spectrosc. 54, 773-782.

Everall, N.J., Lapham, J., Adar, F., Whitley, A., Lee, E., Mamedov, S., 2007. Optimizing depth resolution in confocal Raman microscopy: a comparison of metallurgical, dry corrected, and oil immersion objectives. Appl. Spectrosc. 61, 251-259.

Field, J.E., 1979. The properties of diamond. Academic Press, London New York, 674 p.

Fisher, D., 2009. Brown diamonds and high pressure high temperature treatment. Lithos 112S, 619-624.

Fontaine, F., Deneuville, A., Gheeraert, E., Gonon, P., Abello, L., Lucazeau, G., 1994. Reality of doping by boron implantation of CVD polycrystalline diamond from a comparison of Raman and electrical measurements. Diam. Relat. Mater. 3, 623-627.

Friedland, E., Carstanjen, H.D., Myburg, G., Nasr, M.A., 2005. Dependence of damage efficiency of ions in diamond on electronic stopping. Nucl. Instrum. Meth. B 230, 129-135.

Fukura, S., Nakagawa, T., Kagi, H., 2005. High spatial resolution photoluminescence and Raman spectroscopic measurements of a natural polycrystalline diamond, carbonado. Diam. Relat. Mater. 14, 1950-1954.

Gentry, R.V., 1974. Radiohalos in a radiochronological and cosmological perspective. Science 184, 62-66.

Gippius, A.A., Khmelnitskiy, R.A., Dravin, V.A., Tkachenko, S.D., 1999. Formation and characterization of graphitized layers in ion-implanted diamond. Diam. Relat. Mater. 8, 1631-1634.

Gippius, A.A., Khmelnitsky, R.A., Dravin, V.A., Khomich, A.V., 2003. Diamond-graphite transformation by light ions implantation. Diam. Relat. Mater. 12, 538-541.

Hainschwang, T., Respinger, A., Notari, F., Hartmann, H.J., Günthard, C., 2009. A comparison of diamonds irradiated by high fluence neutrons or electrons, before and after annealing. Diam. Relat. Mater. 18, 1223-1234.

Han, S., Frussin, S.G., Agher, J.W. III, Pan, L.S., Kania, D.R., Lane, S.M., Wagner, R.S., 1993. Radiation damage study of polycrystalline CVD and natural type IIA diamonds using Raman and photoluminescence spectroscopies. Nucl. Instrum. Meth. B 80-81, 1446-1450. 
Hanzawa, H., Umemura, N., Nisida, Y., Kanda, H., Okada, M., Kobayashi, M., 1996. Disorder effects of nitrogen impurities, irradiation-induced defects, and ${ }^{13} \mathrm{C}$ isotope composition on the Raman spectrum in synthetic Ib diamond. Phys. Rev. B 54, 3793-3799.

Hickey, D.P., Jones, K.S., Elliman, R.G., 2009. Amorphization and graphitization of single-crystal diamond - A transmission electron microscopy study. Diam. Relat. Mater. 18, 1353-1359.

Huong, P.V., 1991. Structural studies of diamond films and ultrahard materials by Raman and microRaman spectroscopies. Diam. Relat. Mater. 1, 33-41.

Iakoubovskii, K., Adriaenssens, G.J., 2000. Optical study of some interstitial-related centres in CVD diamond. Phys. Status Solidi A 181, 59-64.

Iakoubovskii, K., Adriaenssens, G.J., Dogadkin, N.N., Shiryaev, A.A., 2001. Optical characterization of some irradiation-induced centers in diamond. Diam. Relat. Mater. 10, 18-26.

Jamieson, D.N., Prawer, S., Nugent, K.W., Dooley, S.P., 1995. Cross-sectional Raman microscopy of MeV implanted diamond. Nucl. Instrum. Meth. B 106, 641-645.

Kagi, H., Sato, S., Akagi, T., Kanda, H., 2007. Generation history of carbonado inferred from photoluminescence spectra, cathodoluminescence imaging, and carbon-isotopic composition. Am. Mineral. 92, 217-224.

Kaiser, W., Bond, W.L., 1959. Nitrogen, a major impurity in common Type I diamond. Phys. Rev. 115, 857-863.

Kalish, R., Prawer, S., 1998. Ion implantation of diamond and diamond films. In: Prelas, M.A., Popovici, G., Bigelow, L.K. (Eds.), Handbook of industrial diamonds and diamond films. Marcel Decker, New York, pp. 945-982.

Kalish, R., Reznik, A., Nugent, K.W., Prawer, S., 1999. The nature of damage in ion-implanted and annealed diamond. Nucl. Instrum. Meth. B 148, 626-633.

Kanada, H., Watanabe, K., 2006. Change of cathodoluminescence spectra of diamond with irradiation of low energy electron beam followed by annealing. Diam. Relat. Mater. 15, 1882-1885.

Khomich, A.V., Khmelnitskiy, R.A., Dravin, V.A., Gippius, A.A., Zaveedev, E.V., Vlasov, I.I., 2007. Radiation damage in diamonds subjected to helium implantation. Phys. Solid State 49, 1661-1665.

Kiflawi, I., Collins, A.T., Iakoubvskii, K., Fisher, D., 2007. Electron irradiation and the formation of vacancy-interstitial pairs in diamond. J. Phys. Condens. Mat. 7, 046216.

Kinny, P.D., Meyer, H.O.A., 1994. Zircon from the mantle: A new way to date old diamonds. J. Geol. 102, 475-481.

Knight, D.S., White, W.B., 1989. Characterization of diamond films by Raman spectroscopy. J. Mater. Res. 4, 385-393.

Koivula, J.I., 2000. The microworld of diamonds. Gemworld International, Inc., Northbrook, 157 p.

Kresten, P., Fels, P., Berggren, G., 1975. Kimberlitic zircons - a possible aid in prospecting for kimberlites. Miner. Deposita 10, 47-56.

Lee, E.H., Hembree, D.M., Jr., Rao, G.R., Mansur, L.K., 1993. Raman scattering from ion-implanted diamond, graphite, and polymers. Phys. Rev. B 48, 15540-15551.

Lind, S.C., Bardwell, D.C., 1923. The coloring and thermophosphorescence produced in transparent minerals and gems by radium radiation. Am. Mineral. 8, 171-180.

Martin, J., Wannemacher, R., Teichert, J., Bischoff, L., Köhler, B., 1999a. Generation and detection of fluorescent color centers in diamond with submicron resolution. Appl. Phys. Lett. 75, 3096-3098.

Martin, J., Grebner, W., Sigle, W., Wannemacher, R., 1999b. Confocal microscopy of color center distributions in diamond. J. Luminesc. 83-84, 493-497.

Mendelssohn, M.J., Milledge, H.J., Vance, E.R., Nave, E., Woods, P.A., 1979. Internal radioactive haloes in diamond. Diamond Research 1979 (DeBeers Indust. Diam. Div.), 31-36.

Meyer, H.O.A., Milledge, H.J., Nave, E., 1965. Natural irradiation damage in Ivory Coast diamonds. Nature 206, 392.

Mikhailov, S.N., Weber, J., Baer, Y., von Kaenel, Y., Stiegler, J., Blank, E., Hänni, W., 1996. Damage and structural modification of CVD diamond films caused by $\alpha$-particles. Nucl. Instrum. Meth. B 118, 753-757. 
Nachalnaya, T.A., Andreyev, V.D., Gabrusenok, E.V., 1994. Shift of the frequency and Stokes-anti-Stokes ratio of Raman spectra from diamond powders. Diam. Relat. Mater. 3, 1325-1328.

Nasdala, L., Wenzel, M., Andrut, M., Wirth, R., Blaum, P., 2001a. The nature of radiohaloes in biotite: experimental studies and modeling. Am. Mineral. 86, 498-512.

Nasdala, L., Wenzel, M., Vavra, G., Irmer, G., Wenzel, T., Kober, B., 2001b. Metamictisation of natural zircon: accumulation versus thermal annealing of radioactivity-induced damage. Contrib. Mineral. Petr. 141, 125-144.

Nasdala, L., Wildner, M., Wirth, R., Groschopf, N., Pal, D.C., Möller, A., 2006. Alpha particle haloes in chlorite and cordierite. Miner. Petrol. 86, 1-27.

Nasdala, L., Grötzschel, R., Probst, S., Bleisteiner, B., 2010. Irradiation damage in monazite $\left(\mathrm{CePO}_{4}\right)$ : An example to establish the limits of Raman confocality and depth resolution. Can. Mineral. 48, 351359.

Nasdala, L., Grambole, D., Götze, J., Kempe, U., Váczi, T., 2011. Helium irradiation study on zircon. Contrib. Mineral. Petr. 161, 777-789.

Nasdala, L., Beyssac, O., Schopf, J.W., Bleisteiner, B., 2012. Application of Raman-based images in the Earth sciences. In: Zoubir, A. (Ed.), Raman imaging: Techniques and applications. Springer Series in Optical Sciences, vol. 168, Springer, Berlin, Heidelberg, pp. 145-187.

Orwa, J.O., Jamieson, D.N., Nugent, K.W., Prawer, S., Kalish, R., 1997. Effects of damage on diffusion of implanted helium in diamond measured by nuclear elastic scattering. Nucl. Instrum. Meth. B 124, 515-518.

Page, F.Z., Fu, B., Kitaa,N., Fournellea, J., Spicuzza, M.J., Schulze,D.J., Vilgoen, F., Basei, M.A.S., Valley, J.W., 2007. Zircons from kimberlite: new insights from oxygen isotopes, trace elements, and Ti in zircon thermometry. Geochim. Cosmochim. Ac. 71, 3887-3903.

Pal, D.C., 2004. Concentric rings of radioactive halo in chlorite, Turamdih uranium deposit, Singhbhum Shear Zone, Eastern India: a possible result of ${ }^{238} \mathrm{U}$ chain decay. Curr. Sci. India 87, 662-667.

Park, J.-W., Kim, H.-J., Kim, Y.-C., 2011. Optical properties of the black diamond produced by ion implantation. J. Mater. Res. 26, 1572-1576.

Prawer, S., Nugent, K.W., Jamieson, D.N., 1998. The Raman spectrum of amorphous diamond. Diam. Relat. Mater. 7, 106-110.

Prins, J.F., Derry, T.E., 2000. Radiation defects and their annealing behaviour in ion-implanted diamond. Nucl. Instrum. Meth. B 166-167, 364-373.

Prins, J.F., Derry, T.E., Sellschop, J.P.F., 1986. Volume expansion of diamond during ion implantation. Phys. Rev. B 34, 8870-8874.

Raineri, V., Galvagno, G., Rimini, E., Biersack, J.P., Nakagawa, S.T., La Ferla, A., Carnera, A., 1991. Channelling implants of B ions into $\langle 100\rangle$ silicon surfaces. Radiat. Eff. Defect. S. 116, 211-217.

Rubanova, E.V., Palazhchenko, O.V., Garanin, V.K., 2009. Diamonds from the V. Grib pipe, Arkhangelsk kimberlite province, Russia. Lithos 112S, 880-885.

Ruschel, K., Nasdala, L., Kronz, A., Hanchar, J.M., Többens, D.M., Škoda, R., Finger, F., Möller, A., 2012. A Raman spectroscopic study on the structural disorder of monazite-(Ce). Miner. Petrol. 105, 41-55.

Schilling, A., 1926. Die radioaktiven Höfe im Flußspat von Wölsendorf. Neues Jb. Miner. Abh. A53, 241265.

Seydoux-Guillaume, A.-M., Wirth, R., Nasdala, L., Gottschalk, M., Montel, J.M., Heinrich, W., 2002. An XRD, TEM and Raman study of experimentally annealed natural monazite. Phys. Chem. Miner. 29, 240-253.

Sharma, S.K., Mao, H.K., Bell, P.M., Xu, J.A., 1985. Measurement of stress in diamond anvils with microRaman spectroscopy. J. Raman Spectrosc. 16, 350-352.

Shelkov, D.A., Verchovsky, A.B., Milledge, H.J., Pillinger, C.T., 1998. The radial distribution of implanted and trapped ${ }^{4} \mathrm{He}$ in single diamond crystals and implications for the origin of carbonado. Chem. Geol. 149, 109-116.

Solin, S.A., Ramdas, A.K., 1970. Raman spectrum of diamond. Phys. Rev. B 1, 1687-1698. 
Spits, R.A., Prins, J.F., Derry, T.E., 1994. A determination of the critical damage density required for "amorphisation" of ion-implanted diamond. Nucl. Instrum. Meth. B 85, 347-351.

Steeds, J.W., Davis, T.J., Charles, S.J., Hayes, J.M., Butler, J.E., 1999. 3H luminescence in electronirradiated diamond samples and its relationship to self-interstitials. Diam. Relat. Mater. 8, 18471852.

Steeds, J.W., Charles, S.J., Davies, J., Griffin, I., 2000. Photoluminescence microscopy of TEM irradiated diamond. Diam. Relat. Mater. 9, 397-403.

Surovtsev, N.V., Kupriyanov, I.N., Malinovsky, V.K., Gusev, V.A., Palyanov, Y.N., 1999. Effect of nitrogen impurities on the Raman line width in diamonds. J. Phys.: Condens. Matter 11, 4767-4774.

Tkachev, V.D., Zaitsev, A.M., Tkachev, V.V., 1985. Chemical activity of noble-gases in diamond. Phys. Status Solidi B 129, 129-133.

Tomašić, N., Gajović, A., Bermanec, V., Su, D., Rajić Linarić, M., Ntaflos, T., Schlögl, R., 2006. Recrystallization mechanisms of fergusonite from metamict mineral precursors. Phys. Chem. Miner. 33, 145-159.

Ustinov, V.N., Zagainyi, A.K., Smith, C.B., Ushkov, V.V., Lazko, E.E., Lukyanova, L.I., Lobkova, L.P., 2009. Early Proterozoic diamond-bearing kimberlites of Karelia and their formation peculiarities.

Russ. Geol. Geophys. 50, 739-750.

Uzan-Saguy, C., Cytermann, C., Brener, R., Richter, V., Shaanan, M., Kalish, R., 1995. Damage threshold for ion-beam induced graphitization of diamond. Appl. Phys. Lett. 67, 1194-1196.

Vance, E.R., Milledge, H.J., 1972. Natural and laboratory $\alpha$-particle irradiation of diamond. Mineral. Mag. 38, 878-881.

Vance, E.R., Harris, J.W., Milledge, H.J., 1973. Possible origins of $\alpha$-damage in diamonds from kimberlite and alluvial sources. Mineral. Mag. 39, 349-360.

Verchovsky, A.B., Ott, U., Begemann, F., 1993. Implanted radiogenic and other noble gases in crustal diamonds from Northern Kazakhstan. Earth Planet. Sc. Lett. 120, 87-102.

Vicenzi, E.P., Heaney, P.J., Snyder, K., Armstrong, L., 2002. Radiation halos, a rare microstructure in diamonds from the Central African Republic. Eos. Trans. AGU, Spring Meet. Suppl., 83, Abstract V31A-10.

Voznyak, D.K., Pavlishin, V.I., Bugaenko, V.N., Galaburda, Yu., 1996. Nature, genetic and geochronological significance of radiogenic haloes in minerals from the Polokhovskoe deposit (Ukrainian Shield) (in Russian). Mineral. Zh. 18, 3-7.

Walker, J., 1979. Optical absorption and luminescence in diamond. Rep. Prog. Phys. 42, 1650-1659.

Wang, W., Cheung, C.C., Gelb, T., 2006. Diamond with circular brown or green radiation stains. Gems Gemol. 42, 161-162.

Weikusat, C., Miletich, R., Glasmacher, U.A., Trautmann, C., Neumann, R., 2010. Heavy ion irradiation on crystallographically oriented cordierite and the conversion of molecular $\mathrm{CO}_{2}$ to $\mathrm{CO}-\mathrm{A}$ Raman spectroscopic study. Phys. Chem. Miner. 37, 417-424.

Yagiu, H., Deguchi, M., Won, H.J., Mori, Y., Hatta, A., Kitabatake, M., Ito, T., Hirao, T., Hiraki, A., 1995. Ion implantation in CVD diamond and plasma treatment effect. Diam. Relat. Mater. 4, 575-579.

Yoshikawa, M., Mori, Y., Maegawa, M., Katagiri, G., Ishida, H., Ishitani, A., 1993. Raman scattering from diamond particles. Appl. Phys. Lett. 62, 3114-3116.

Zaitsev, A.M., 2001. Optical properties of diamond. Springer, Berlin Heidelberg New York, 502 p.

Zhao, X.-Z., Cherian, K.A., Roy, R., White, W.B, 1998. Downshift of Raman peak in diamond powders. J. Mater. Res. 13, 1974-1976.

Ziegler, J.F., Biersack, J.P., Littmark, U., 1985. The stopping and range of ions in solids. In: Ziegler. J.F. (Ed.), The stopping and ranges of ions in matter, vol. 1. Pergamon, New York.

Ziegler, J.F., Biersack, J.P., Ziegler, M.D., 2008. SRIM - The Stopping and Range of Ions in Matter. SRIM Co. (ISBN 0-9654207-1-X). 
Table 1

Raman data* for green (as-irradiated) and brown He-irradiated spots (subsequently heated at $550{ }^{\circ} \mathrm{C}$; see Fig. 7).

\begin{tabular}{lcccc}
\hline He fluence & Heating T & \multicolumn{3}{c}{ FWHM $\left[\mathrm{cm}^{-1}\right]^{* *}$} \\
& & $15 \mu \mathrm{m}$ & $29 \mu \mathrm{m}$ & $>50 \mu \mathrm{m}$ \\
\hline $10^{14} / \mathrm{cm}^{2}$ & - & $1.7 \pm 0.2$ & $2.1 \pm 0.2$ & $1.7 \pm 0.2$ \\
$10^{14} / \mathrm{cm}^{2}$ & $550^{\circ} \mathrm{C}$ & $1.8 \pm 0.2$ & $1.8 \pm 0.2$ & $1.8 \pm 0.2$ \\
$10^{15} / \mathrm{cm}^{2}$ & - & $1.9 \pm 0.2$ & $8.3 \pm 0.5$ & $1.7 \pm 0.2$ \\
$10^{15} / \mathrm{cm}^{2}$ & $550^{\circ} \mathrm{C}$ & $1.9 \pm 0.2$ & $3.3 \pm 0.4$ & $1.8 \pm 0.2$ \\
$10^{16} / \mathrm{cm}^{2}$ & - & $2.3 \pm 0.2$ & n.d. & $1.7 \pm 0.2$ \\
$10^{16} / \mathrm{cm}^{2}$ & $550^{\circ} \mathrm{C}$ & $2.1 \pm 0.2$ & $6.0 \pm 0.5$ & $1.7 \pm 0.2$ \\
$10^{17} / \mathrm{cm}^{2}$ & - & $5.0 \pm 0.3$ & n.d. & $1.7 \pm 0.2$ \\
$10^{17} / \mathrm{cm}^{2}$ & $550^{\circ} \mathrm{C}$ & $3.1 \pm 0.2$ & n.d. & $1.8 \pm 0.2$ \\
\hline
\end{tabular}

* Raman data for samples irradiated with $10^{13} \mathrm{He} / \mathrm{cm}^{2}$ did not show measurable changes and are therefore not reported here.

** FWHMs (corrected for the apparatus function) of the diamond $L O=T O$ band, measured at three different depths below the irradiated surface.

n.d.: no Raman signal of diamond detected

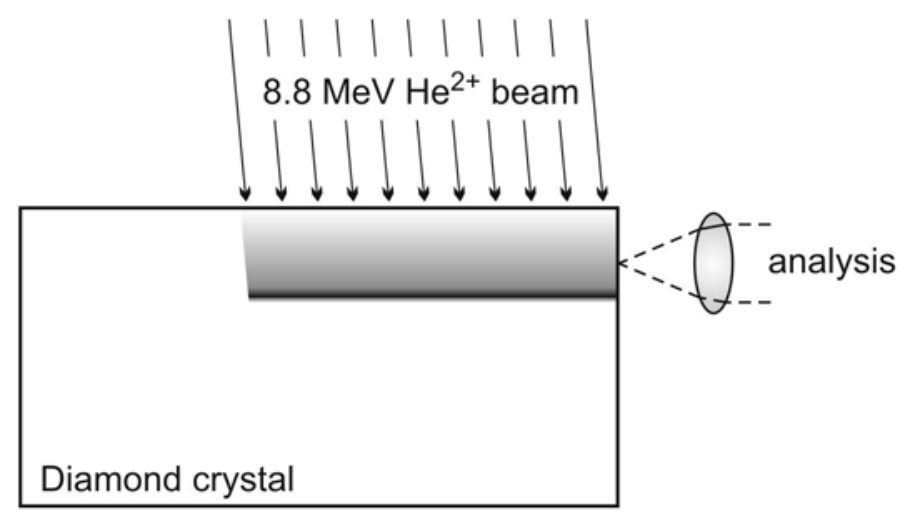

Fig. 1. Schematic sketch (not to scale) of a sample subjected to ion-irradiation and subsequent spectroscopy. One main face of the doubly polished slice was ion-irradiated at an angle of $7^{\circ}$ to the normal; Raman depth-profiling was then made through a small polished face that was prepared beforehand perpendicular to the main surface. 

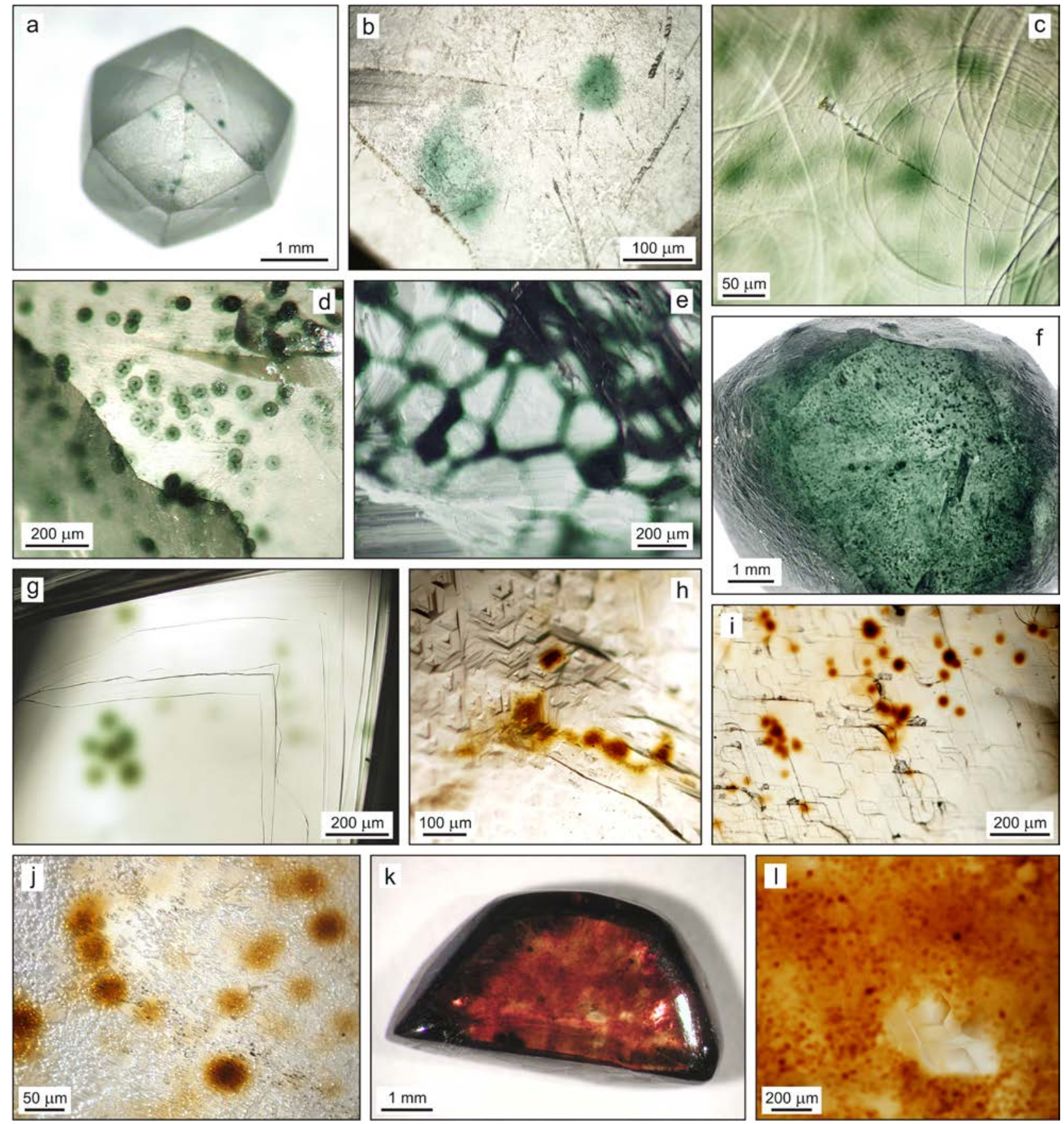

Fig. 2. (overleaf) Representative photographs of radio-coloured diamond specimens. (a) Crystal from Langkorte, Namaqualand, RSA, with a few dull green spots. (b) Close-up of the same specimen. (c) Multitude of oval to fuzzy, green spots at the surface of a diamond from Barou De Manoles, Brazil. (d) Circular green haloes on the surface of a diamond of unknown origin that show the rare phenomenon of central, tiny entities or crystals. (e) Meshwork staining pattern on a corroded diamond from the Matto Grosso region, Brazil. (f) Intensely green-spotted rough stone of unknown origin. (g) Well-shaped, circular green spots at an octahedron from Guaniamo, Venezuela. (h) Round or cloudy-elongated, orange to dark brown spots at the surface of a stone from the Jatobá river, Brazil. (i,j) Circular orange-brown spots on two rough diamonds from Namaqualand, RSA. (k) Intensely coloured stone from the Central African Republic. (l) Close-up of the same specimen, showing that its brown colouration is due to thousands of small, circular spots. Subfigures $\mathrm{d}-\mathrm{f}$ come from the photograph collection of George Bosshart (deceased). 

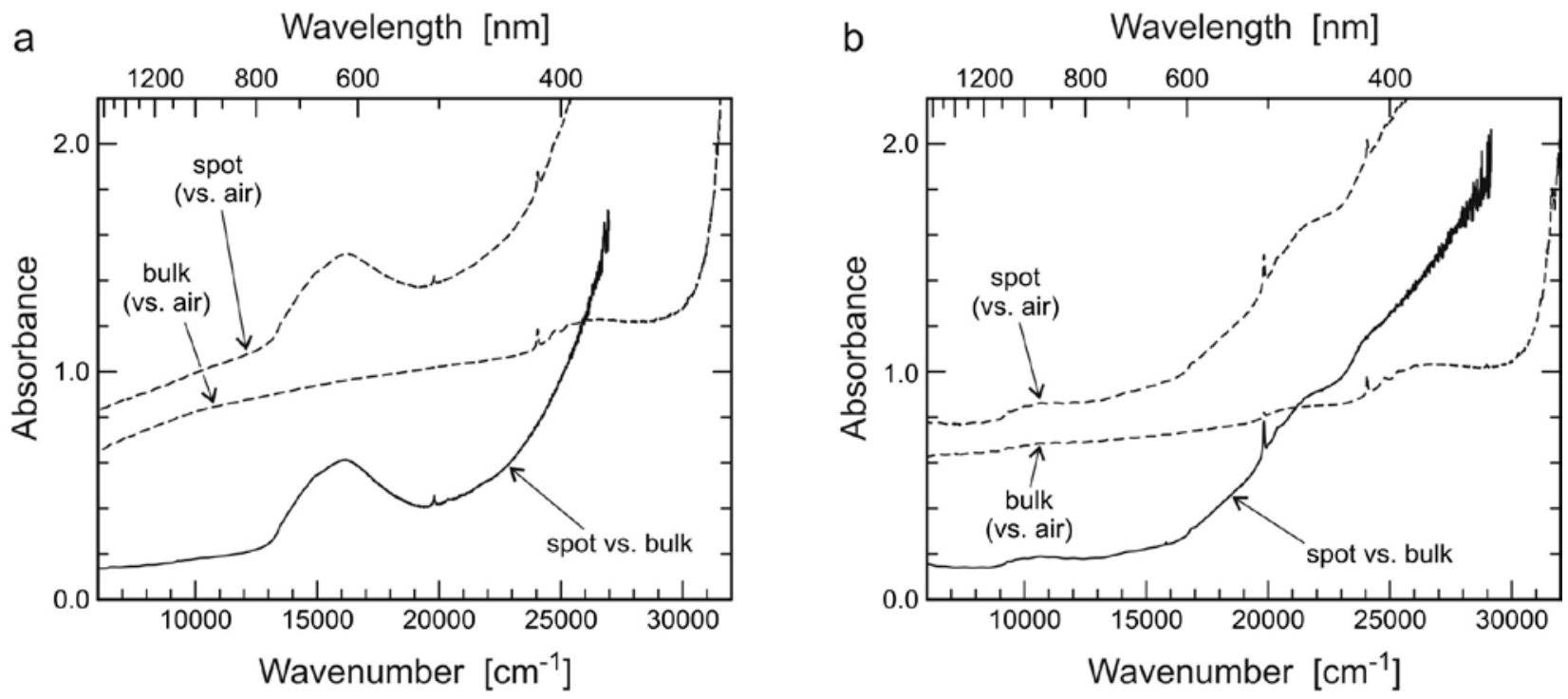

Fig. 3. Representative optical absorption spectra of a green (a) and a brown spot (b) on two rough diamond specimens from Namaqualand, RSA. The solid graphs represent the effective radio-colouration; they were calculated from the difference of the absorptions of spot and bulk (dashed). 

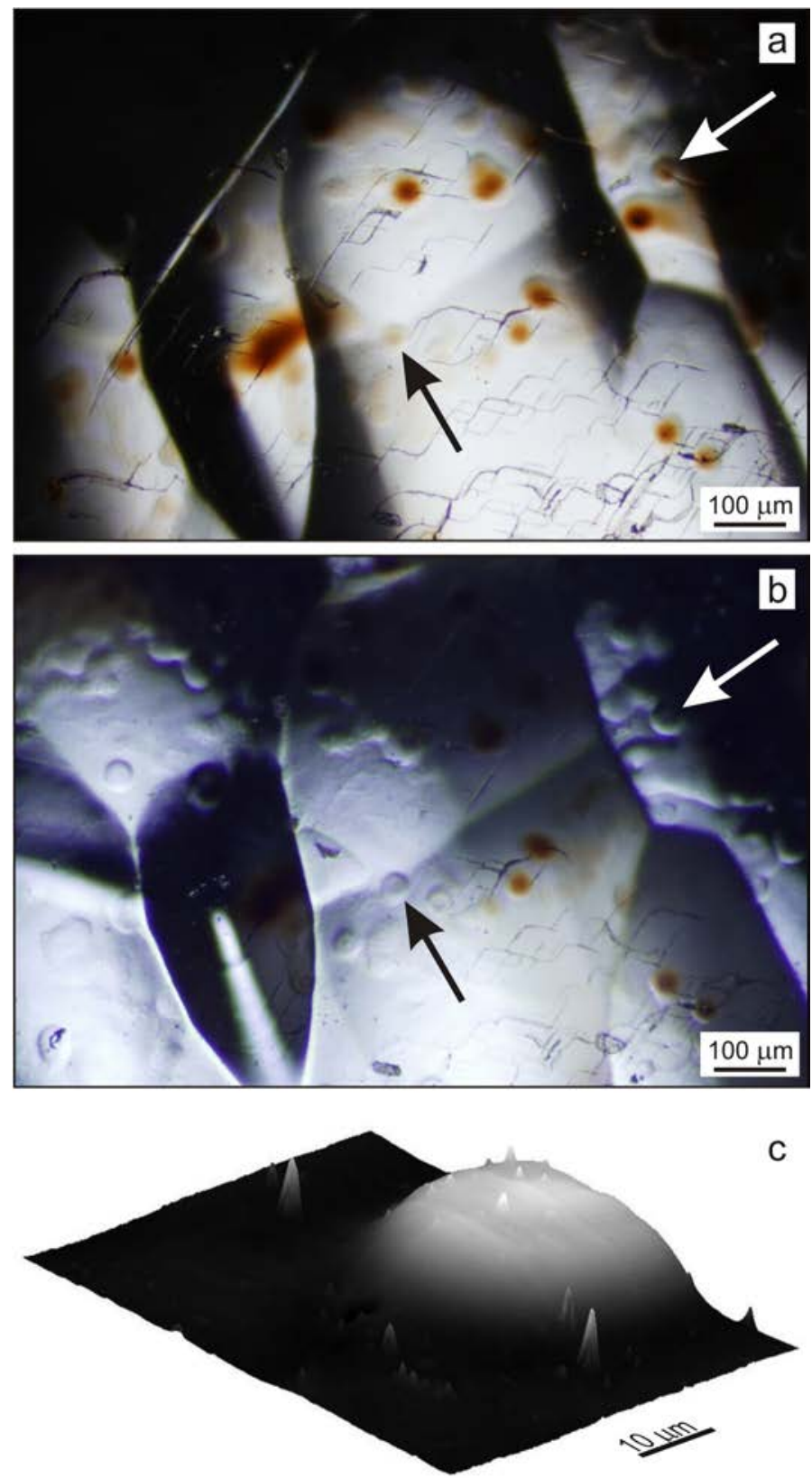

Fig. 4. Surface up-doming resulting from the volume expansion inside radiohaloes. (a) Reflected light photomicrograph of the (110) face of a brown-spotted diamond from Namaqualand, RSA. (b) Image of the very same area, low-angle reflected light. The spots (two examples are marked with arrows) are seen as droplet-like, convex surface bulges. (c) Surface topography scan (AFM) across one individual radio-spot. The spot is seen as a broad hump (diameter $\sim 36 \mu \mathrm{m}$, height $\sim 400 \mathrm{~nm}$ ); small peaks are artefacts (dust particles at the surface). 


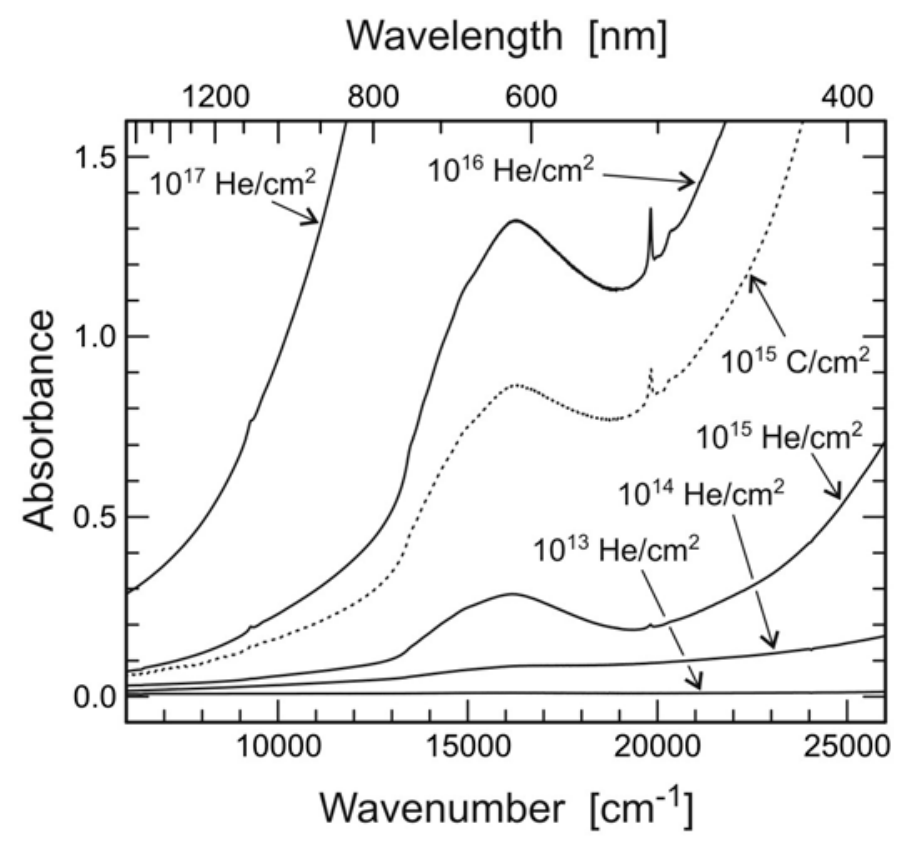

Fig. 5. Optical absorption spectra (spots vs. bulk; solid graphs) of green spots produced by irradiation of diamond with various fluences of $8.8 \mathrm{MeV} \mathrm{He}^{2+}$ ions (solid graphs). The spectrum of a green spot irradiated with $22.5 \mathrm{MeV} \mathrm{C}^{4+}$ ions (fluence $10^{15}$ per $\mathrm{cm}^{2}$; dotted graph) is shown for comparison.

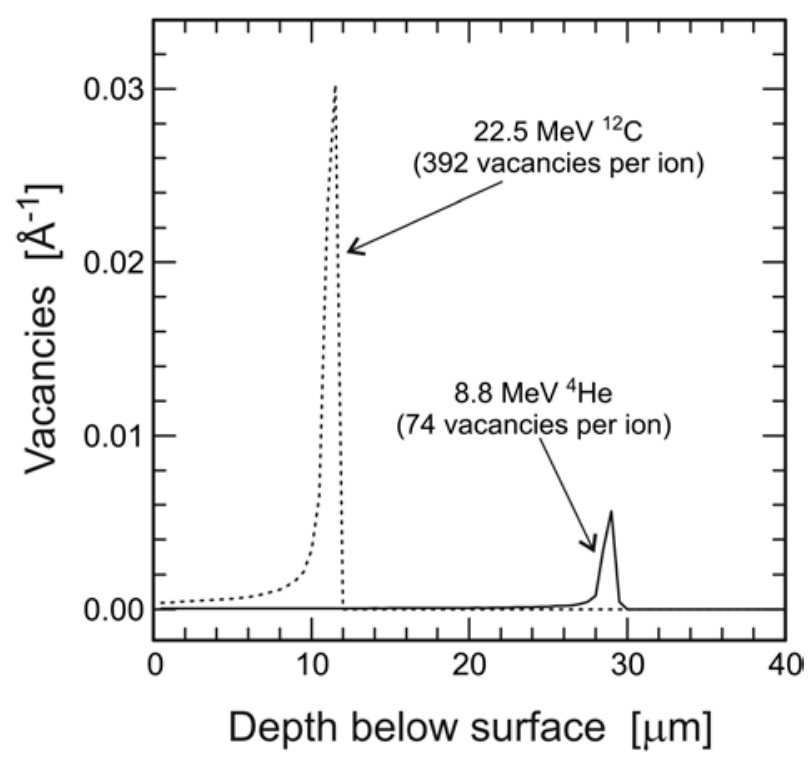

Fig. 6. Distribution of point defects in a diamond target created per ion irradiated, as predicted by SRIM calculation. 

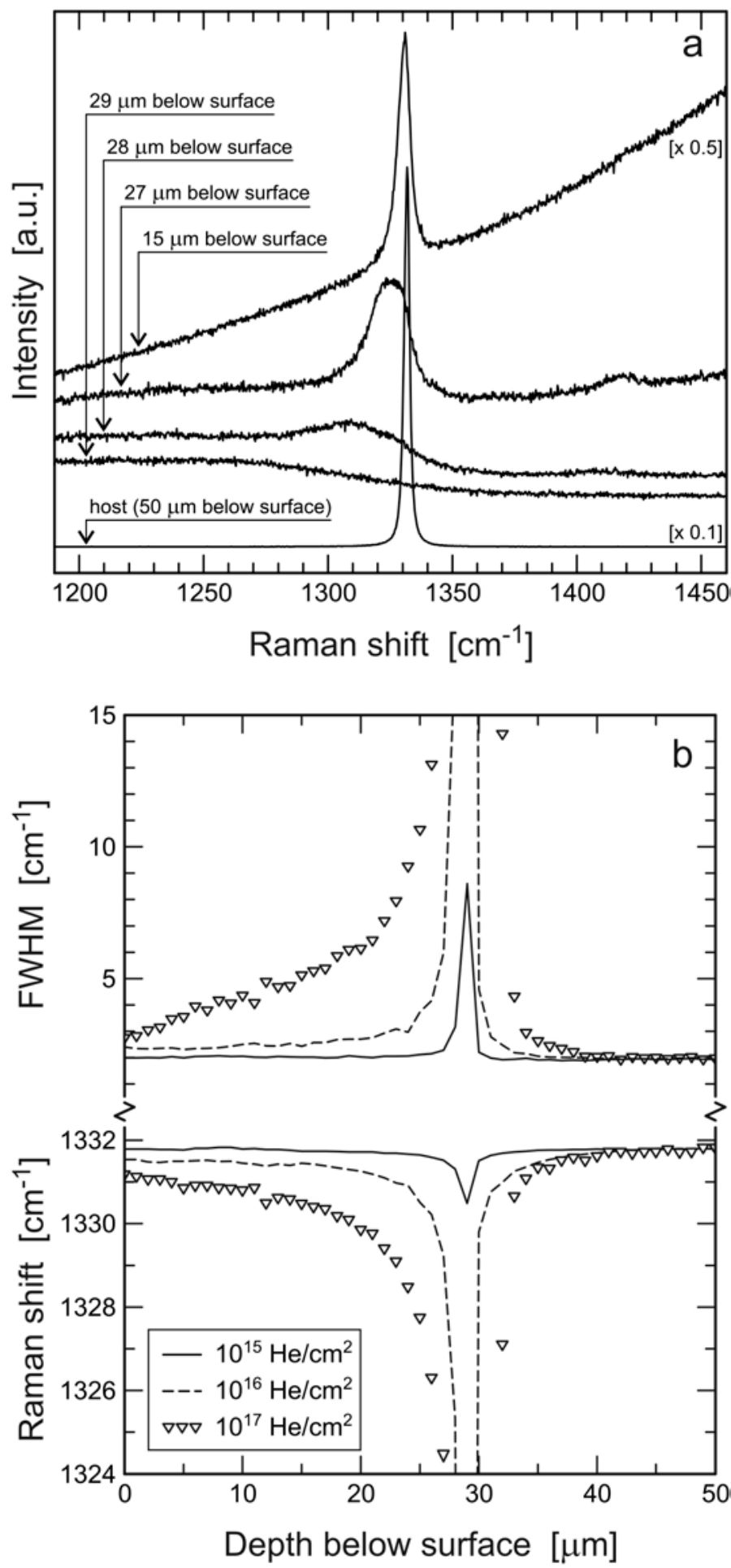

Fig. 7. Raman analysis of diamond irradiated with $8.8 \mathrm{MeV} \mathrm{He}^{2+}$ ions. (a) Selected Raman spectra of the spot irradiated with a fluence of $10^{17}$ ions $/ \mathrm{cm}^{2}$, obtained at different depths below the irradiated surface. (b) Depth profiles of Raman spectral parameters (position and FWHM of the diamond $L O=T O$ band) for three spots $\left(10^{15}-10^{17}\right.$ ions $\left./ \mathrm{cm}^{2}\right)$. 


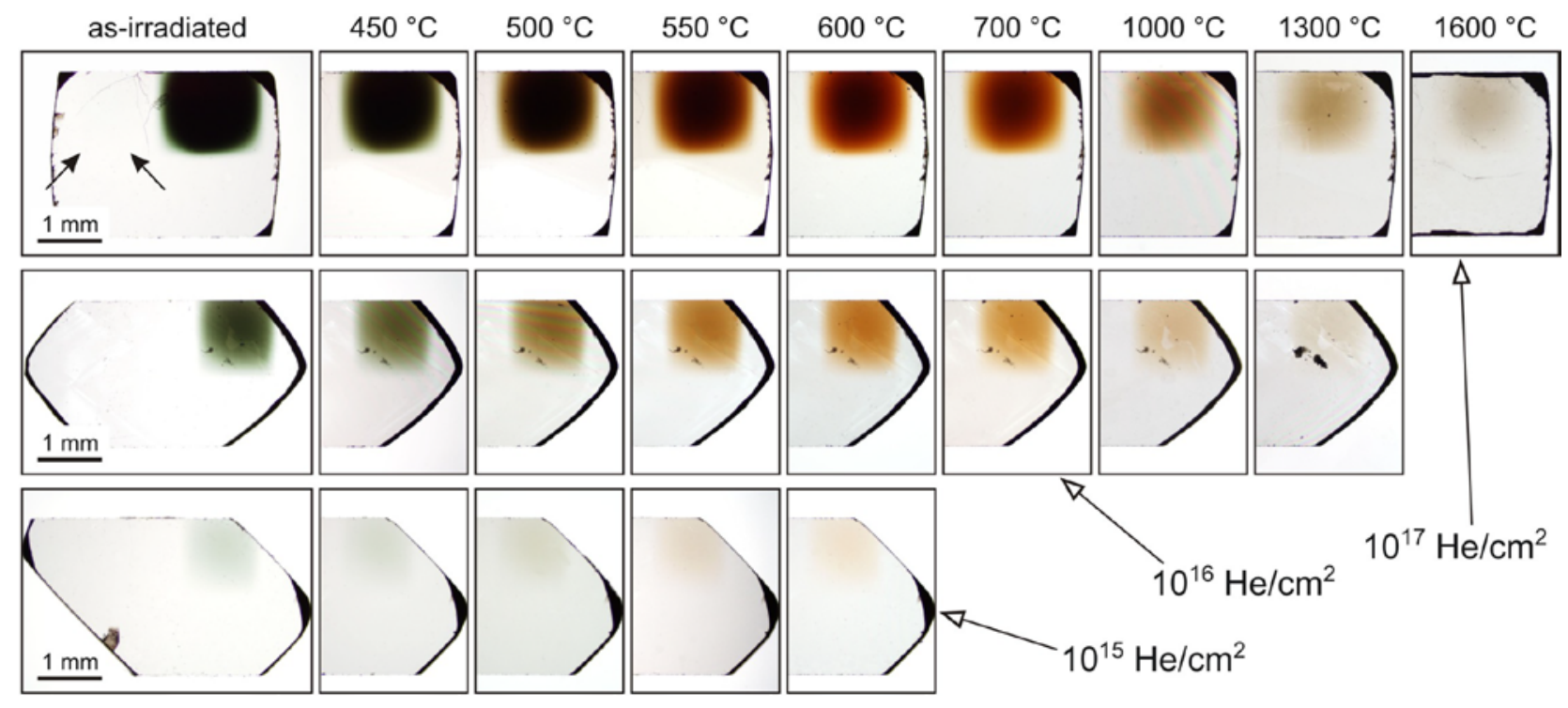

Fig. 8. Colour change (green-brown) and subsequent de-colouration upon step-wise annealing of three spots produced by the irradiation of diamond plates with $8.8 \mathrm{MeV} \mathrm{He}^{2+}$ ions. Note that the slice shown in the upper row of images was also irradiated with $10^{14} \mathrm{He} / \mathrm{cm}^{2}$ (area left of the dark green $10^{17} \mathrm{He} / \mathrm{cm}^{2}$ spot marked with two black arrows). The $10^{14} \mathrm{He} / \mathrm{cm}^{2}$ spot however cannot be recognised in the upper left photograph due to its extremely low colouration intensity. 

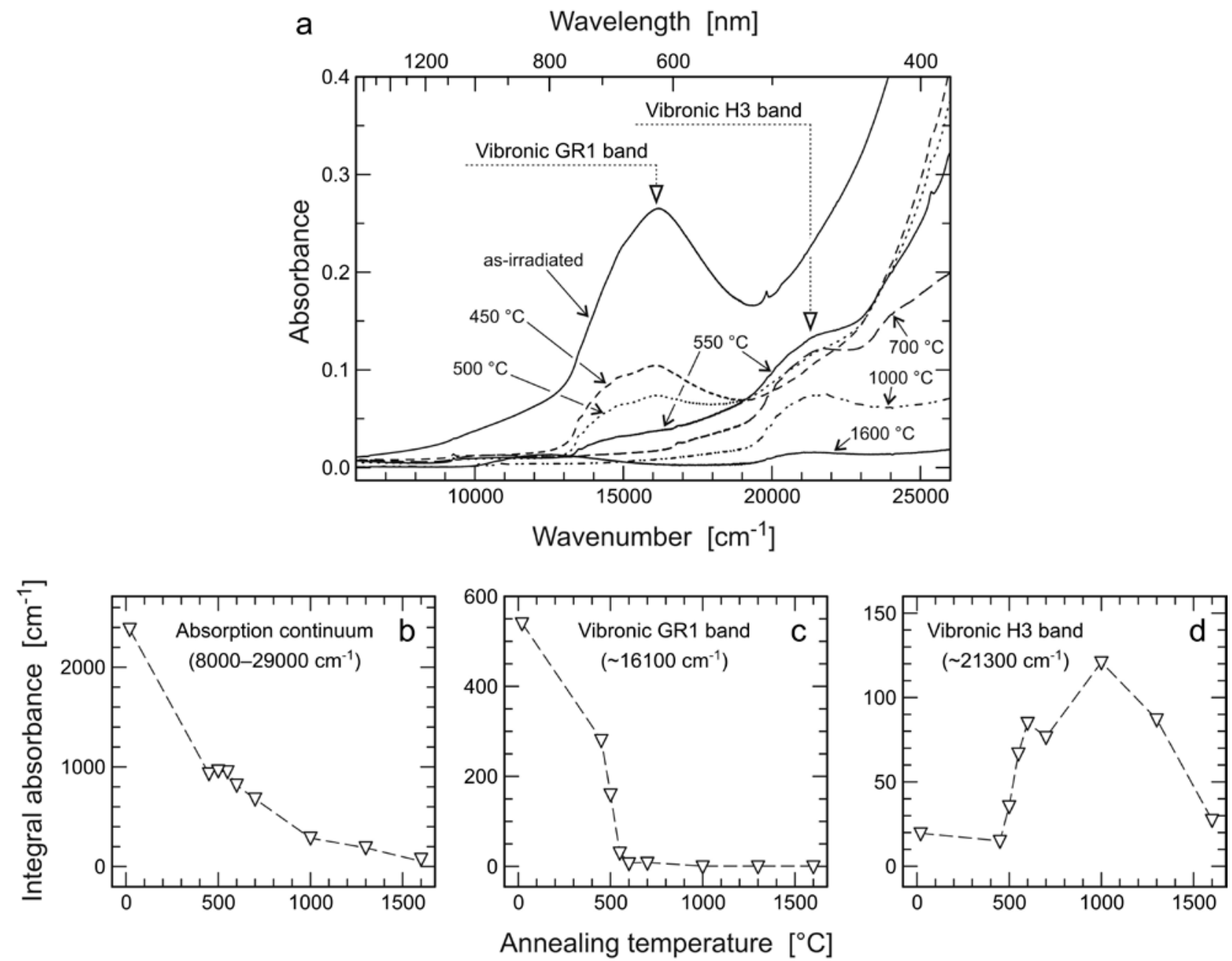

Fig. 9. Spectral changes of the optical absorption upon annealing, for the example of the spot irradiated with $10^{15} \mathrm{He}^{2+}$ ions $/ \mathrm{cm}^{2}$. (a) Selected optical absorption spectra (spots vs. bulk). Spectra after annealing at $600{ }^{\circ} \mathrm{C}$ and $1300{ }^{\circ} \mathrm{C}$ are not shown for more clarity of the presentation. (b-d) Three plots of the integral absorbance vs. annealing temperature, showing significantly different trends for individual absorption features. 



Fig. 10. Photoluminescence of brown irradiation spots. (a) PL image ( $\leq 370 \mathrm{~nm}$ UV illumination; taken at room temperature) of a diamond plate irradiated with $8.8 \mathrm{MeV} \mathrm{He}^{2+}$ ions $\left(10^{16} \mathrm{ions} / \mathrm{cm}^{2}\right.$; upper left spot; $10^{13}$ ions $/ \mathrm{cm}^{2}$; extremely faint spot at the lower left $)$ and $22.5 \mathrm{MeV} \mathrm{C}^{4+}$ ions $\left(10^{15} \mathrm{ions} / \mathrm{cm}^{2}\right.$; lower right spot), after annealing at $1000^{\circ} \mathrm{C}$. (b) Typical PL spectrum of a yellowish-green emitting spot in comparison with the virtually non-luminescent host (obtained at $-196^{\circ} \mathrm{C} ; 473 \mathrm{~nm}$ laser excitation). The asterisk marks the diamond $L O=T O$ Raman band.

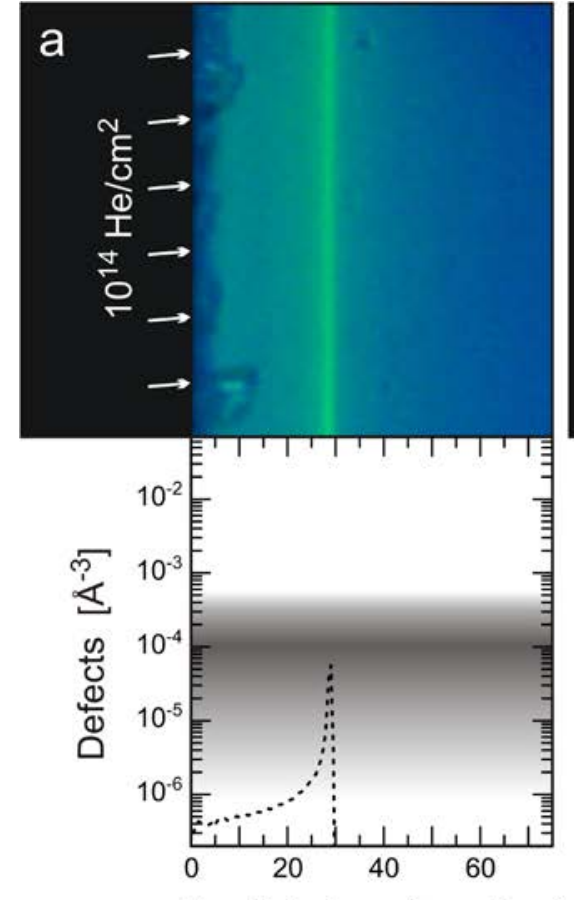

Depth bel. surface $[\mu \mathrm{m}]$
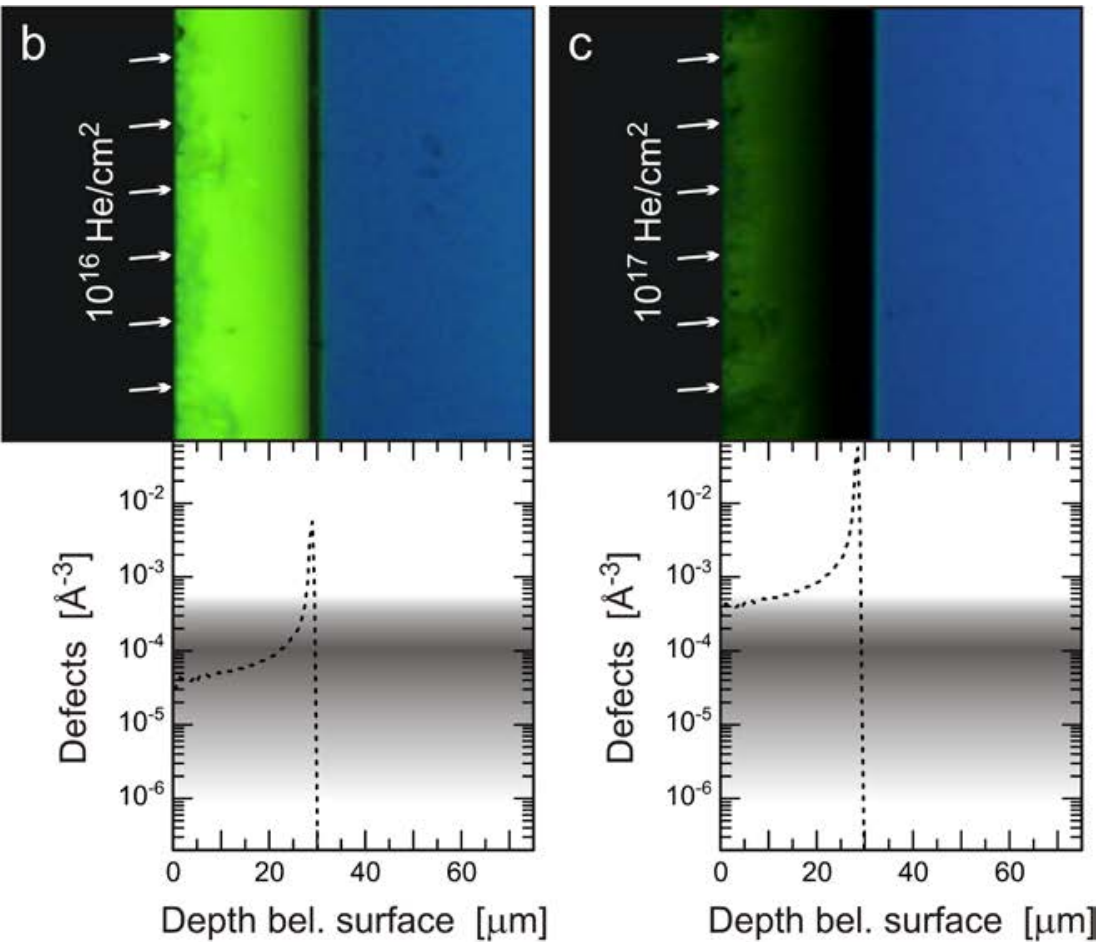

Fig. 11. Evolution of the UV-induced PL of diamond after annealing at $1000{ }^{\circ} \mathrm{C}$, which is dependent on the irradiation fluence. The depth distributions of the emission intensity (PL images, top) correspond well with the predicted defect-density distributions (below). The narrow defect-density range between onset and suppression of visible PL is visualised as a gray bar. 